\title{
Molecular characterization of dissolved organic matter from subtropical wetlands: a comparative study through the analysis of optical properties, NMR and FTICR/MS
}

\author{
Norbert Hertkorn $^{1}$, Mourad Harir ${ }^{1}$, Kaelin M. Cawley ${ }^{2}$, Philippe Schmitt-Kopplin ${ }^{1}$, and Rudolf Jaffé2 \\ ${ }^{1}$ Helmholtz Zentrum München, German Research Center for Environmental Health, Research Unit Analytical \\ Biogeochemistry (BGC), Ingolstädter Landstrasse 1, 85764 Neuherberg, Germany \\ ${ }^{2}$ Southeast Environmental Research Center, and Department of Chemistry and Biochemistry, Florida International University, \\ 11200 SW 8th Street, Miami, FL 33199, USA
}

Correspondence to: Rudolf Jaffé (jaffer@fiu.edu)

Received: 23 July 2015 - Published in Biogeosciences Discuss.: 25 August 2015

Revised: 22 December 2015 - Accepted: 7 February 2016 - Published: 19 April 2016

\begin{abstract}
Wetlands provide quintessential ecosystem services such as maintenance of water quality, water supply and biodiversity, among others; however, wetlands are also among the most threatened ecosystems worldwide. Natural dissolved organic matter (DOM) is an abundant and critical component in wetland biogeochemistry. This study describes the first detailed, comparative, molecular characterization of DOM in subtropical, pulsed, wetlands, namely the Everglades (USA), the Pantanal (Brazil) and the Okavango Delta (Botswana), using optical properties, high-field nuclear magnetic resonance (NMR) and ultrahigh-resolution mass spectrometry (FT-ICRMS), and compares compositional features to variations in organic matter sources and flooding characteristics (i.e., differences in hydroperiod). While optical properties showed a high degree of variability within and between the three wetlands, analogies in DOM fluorescence properties were such that an established excitation emission matrix fluorescence parallel factor analysis (EEMPARAFAC) model for the Everglades was perfectly applicable to the other two wetlands. Area-normalized ${ }^{1} \mathrm{H}$ NMR spectra of selected samples revealed clear distinctions of samples while a pronounced congruence within the three pairs of wetland DOM readily suggested the presence of an individual wetland-specific molecular signature. Within sample pairs (long- vs. short-hydroperiod sites), internal differences mainly referred to intensity variations (denoting variable abundance) rather than to alterations of NMR resonances positioning (denoting diversity of molecules). The
\end{abstract}

relative disparity was largest between the Everglades longand short-hydroperiod samples, whereas Pantanal and Okavango samples were more alike among themselves. Otherwise, molecular divergence was most obvious in the case of unsaturated protons $\left(\delta_{\mathrm{H}}>5 \mathrm{ppm}\right)$. 2-D NMR spectroscopy for a particular sample revealed a large richness of aliphatic and unsaturated substructures, likely derived from microbial sources such as periphyton in the Everglades. In contrast, the chemical diversity of aromatic wetland DOM likely originates from a combination of higher plant sources, progressive microbial and photochemical oxidation, and contributions from combustion-derived products (e.g., black carbon). FT-ICRMS spectra of both Okavango and Pantanal showed near $57 \pm 2 \% \mathrm{CHO}, 8 \pm 2 \% \mathrm{CHOS}, 33 \pm 2 \% \mathrm{CHNO}$ and $<1 \%$ CHNOS molecules, whereas those of Everglades samples were markedly enriched in CHOS and CHNOS at the expense of $\mathrm{CHO}$ and $\mathrm{CHNO}$ compounds. In particular, the Everglades short-hydroperiod site showed a large set of aromatic and oxygen-deficient "black sulfur" compounds whereas the long-hydroperiod site contained oxygenated sulfur attached to fused-ring polyphenols. The elevated abundance of CHOS compounds for the Everglades samples likely results from higher inputs of agriculture-derived and sea-spray-derived sulfate. Although wetland DOM samples were found to share many molecular features, each sample was unique in its composition, which reflected specific environmental drivers and/or specific biogeochemical processes. 


\section{Introduction}

Natural dissolved organic matter (DOM) is a critical component of the global carbon cycle (Battin et al., 2009). It serves as an energy resource fueling the microbial loop (Amon and Benner, 1996a), acts as a carrier facilitating the mobilization of trace metals and combustion derived products (Yamashita and Jaffé, 2008; Jaffé et al., 2013), and functions as a sun screen for aquatic organisms by limiting light penetration (Blough and Green, 1995; Foden et al., 2008) among other biogeochemical processes. In addition to comprising one of the largest organic matter pools in aquatic environments, DOM is one of the most complex mixtures of organic matter in natural systems containing millions of organic compounds (Koch et al., 2005; Hertkorn et al., 2008). While the molecular characterization of DOM (Hertkorn et al., 2006, 2013; Jaffé et al., 2014; Woods et al., 2011 and 2012; Panagiotopolous et al., 2007; Lam et al., 2007; Aluwihare and Repeta, 1999) has significantly advanced our understanding of its composition and ecological functions, a significant portion of this material remains uncharacterized at the molecular level. Although molecular similarities between bulk DOM from vastly different environments have been reported (Repeta et al., 2002; Perdue and Ritchie, 2003; Jaffé et al., 2012; Hertkorn et al., 2013), the variability in composition (quality) among samples can also be quite significant (Jaffé et al., 2008; Zhang et al., 2014) implying differences in the photo- and bio-reactivity of these materials (Amon and Benner, 1996b). Such compositional differences (or similarities) may have important implications with regard to carbon cycling and the ecological functioning of DOM. While the characterization of DOM using targeted substrates such as amino acids (Yamashita and Tanoue, 2003), neutral sugars (Panagiotopolous et al., 2007), lignin phenols (Spencer et al., 2012) and others have actively been pursued, much of the bulk DOM remains uncharacterized (Hedges et al., 2000) and broader spectrum analyses are required. As such, multianalytical approaches for the advanced molecular characterization of DOM are needed to advance this field (Hertkorn et al., 2013; Jaffé et al., 2012; Minor et al., 2014).

During synthesis of natural DOM, common biosignatures characteristic of the respective sources are progressively attenuated by the combined action of biotic and abiotic reactions. While degradative analysis of DOM intentionally destroys the sample in the beginning to recover a suite of known decomposition products, such as amino acids, carbohydrates, lignin phenols and lipids (which typically account for about 5-30\% of the organic carbon, depending on age, environment and diagenesis), non-target molecular-level analyses of DOM attempt to characterize the entire carbon pool present in DOM by means of information-rich detection methods, such as UV-Vis, fluorescence, NMR spectroscopy and FTICRMS. While optical properties have been widely applied for DOM bulk characterizations (Jaffé et al., 2014; Fellman et al., 2010) and allow large sample throughput at low cost, more advanced molecular level characterization techniques such as NMR provide unsurpassed insight into closerange molecular order (Hertkorn et al., 2006, 2013; Lam et al., 2007; McCaul et al., 2011; Woods et al., 2011, 2012; Zhang et al., 2014; Bell et al., 2015), while FT-ICRMS provides depiction of the compositional space with exceptional resolution (Kujawinski, 2002; Sleighter and Hatcher, 2007; D'Andrilli et al., 2010; Hertkorn et al., 2008, 2013; Kaiser et al., 2003; Minor et al., 2014; Koch et al., 2005, 2007). The combination of such techniques in the assessment of DOM dynamics has become more frequent (e.g., Tfaily et al., 2015; Jaffé et al., 2012), and furthermore, the association between optical properties and the molecular characteristics of DOM have recently become an active research endeavor in an attempt to better link these parameters (Stubbins et al., 2014; Kellerman et al., 2015; Wagner et al., 2015a). As such, this work should provide further advances in this field.

While significant efforts have been devoted to the detailed characterization of DOM in oceanic, lacustrine and riverine environments (Hertkorn et al., 2013; Kujawinski et al., 2009; Einsiedl et al., 2007; Minor et al., 2012; Jaffé et al., 2012), still little is known about its molecular features in large freshwater wetlands - environments that are critically threatened by anthropogenic influences such as pollution and drainage for flood control, agricultural and urban development. Organic matter dynamics in large wetlands are particularly complex (e.g., Chen et al., 2013; Yamashita et al., 2010; Cawley et al., 2012) due to a high variability in spatial and temporal organic matter sources, concentrations and diagenetic transformations. These variations are to a large extent driven by interplay between complex hydrological and primary productivity patterns. In this study, DOM samples from three of the largest and most important subtropical, pulsed wetlands - the Everglades (USA), the Pantanal (Brazil) and the Okavango Delta (Botswana) - were collected and analyzed on a comparative basis using optical properties, including EEM-PARAFAC, high-field ${ }^{1} \mathrm{H}$ NMR, ${ }^{13} \mathrm{C}$ NMR and FT-ICRMS, in order to assess similarities and differences in DOM composition and molecular structure in such vital ecosystems.

\section{Experimental}

\subsection{Site descriptions, sample collection and analysis}

The Everglades, Okavango Delta and Pantanal are three of the largest subtropical, pulsed, freshwater wetlands in the world and represent a wealth of biodiversity (Junk et al., 2006a). The Everglades ecosystem is a large (610 $483 \mathrm{ha}$ ) subtropical wetland located in southern Florida, USA. Annually, the southern section of the system, namely the Everglades National Park, receives ca. $120 \mathrm{~cm}$ of precipitation (50-year averages from 1962-2012) with $21 \mathrm{~cm}$ falling during the dry season (December to April) and $99 \mathrm{~cm}$ falling during the wet season (May to November) (Southeast Regional 
Climate Center, http://www.sercc.com). The freshwater area of the Everglades consists primarily of grassy marshes dominated by saw grass (Cladium jamaicense) with some small stands of trees on higher ground. The freshwater marshes drain through two main slough areas, namely the peat-soildominated Shark River Slough and the less extensive, marlsoil-based Taylor Slough, which are characterized by longer and shorter hydroperiods (time and depth of inundation), respectively.

The Okavango Delta is a large wetland located in semiarid NW Botswana and is subject to an annual flood event generated by water of the Okavango River flowing south from the highlands of Angola. During the flood event, the inundated area in the Delta expands in size from the annual minimum of $3500-6000 \mathrm{~km}^{2}$ to the annual maximum of 9000-13000 km² (Gieske, 1997; McCarthy et al., 2003). About $88 \%$ of inflowing water leaves the wetland through evaporation (Wolski et al., 2006). Flood water moves in the Okavango Delta as a combination of channel and floodplain flows. Several zones featuring differences in hydroperiod due to the seasonality of inundation are categorized as the panhandle, permanent swamp, seasonal floodplains and occasional floodplains (Gumbricht et al., 2004; Cawley et al., 2012). The permanent swamp is characterized by extensive peat development and dominated by Phragmites australis and $C$. papyrus (Ellery et al., 2003; Mladenov et al., 2007). The seasonal floodplains are less peat rich and support mostly emergent sedges and aquatic macrophytes, while the occasional floodplains, characterized by the shortest hydroperiod, are dominated by aquatic grasses.

The Pantanal is a large inland wetland of ca. $160000 \mathrm{~km}^{2}$, located mostly in SE Brazil, but also extends into Bolivia and Paraguay (Junk and da Cunha, 2005; Junk et al., 2006b). The regional geology (depression) features natural levees along stream channels, and thus the wetland is comprised of a labyrinth of large river channels, small streams, canals and lagoons. Climate conditions lead to clear wet and dry seasons creating a monomodal flood pulse system. The wetland discharges about $80 \%$ of its water to the Paraguay River in the southern section of the system. The climate is tropical to subtropical with a large number of habitats including savannas and dry forests, leading to broad species diversity. While still mostly pristine, the expansion of cattle ranching surrounding the protected national park and hydrological modifications in the greater watershed have been suggested as potential threats to this ecosystem (Junk and da Cunha, 2005).

Surface water grab samples for the three above-described wetlands were collected in pre-cleaned, brown plastic bottles (60 $\mathrm{mL}$ for DOC and optical properties; $2 \mathrm{~L}$ for solid phase extracts; SPE-DOM), placed on ice and filtered through GFF $(0.7 \mu \mathrm{m}$ nominal pore size $)$, pre-combusted glass fiber filters within $6 \mathrm{~h}$ after collection. For EEM-PARAFAC comparisons, multiple samples collected monthly over several years for the FCE ( $n=858$; Chen et al., 2013), samples collected along a trans-Okavango gradient $(n=38$; Caw- ley et al., 2012) and samples collected in different subenvironments of the Pantanal wetland ( $n=22$; rivers, lagoons, marshes; unpublished) were used to assess differences and similarities in the fluorescence character of the DOM. Sampling for SPE-DOM was performed during summer 2011 for the Florida coastal Everglades (FCE) and during summer 2010 for the Pantanal (PAN) and the Okavango Delta (OKA) as part of ongoing research programs. Only two SPE-DOM samples from each wetland were selected for detailed NMR and FTICRMS analyses, and consisted of one sample characteristic for long-hydroperiod (-L) and one for short-hydroperiod (-S) environments for each wetland respectively. For the Florida Coastal Everglades (FCE), samples were collected from the freshwater marsh, peatsoil-dominated Shark River Slough (FCE-L) and the marlsoil-dominated Taylor Slough (FCE-S), from the Okavango Delta (OKA) seasonal floodplain (OKA-L) and occasional floodplain (OKA-S) along the Boro River (Cawley et al., 2012), and the Paraguay River (PAN-L) and a wetland channel in Pantanal National Park (PAN-S; Chacra de Solange) for the Pantanal (PAN). Representative sample selection for long- and short-hydroperiod sites was based on previous reports for the FCE and OKA (Chen et al., 2013; Cawley et al., 2012), and advice from local wetlands scientists for the PAN (C. Nunes da Cunha, personal communication, 2010). The filtered samples were subjected to SPE isolation (Dittmar et al., 2008). Briefly, samples were acidified to a $\mathrm{pH} 2$ using concentrated $\mathrm{HCl}$. DOM in the acidified samples was extracted using PPL (Varian Bond Elut) cartridges and eluted with methanol (Optima, Fisher). The isolated SPE-DOM extracts (referred to from here on as DOM for the NMR and FTICRMS data) were stored in pre-combusted glass vials and kept in a freezer until analyzed. Milli-Q water was used as a procedural blank and no contamination was observed. DOC measurements were made within 3 weeks of sample collection at the Southeast Environmental Research Center's water quality lab at Florida International University with a Shimadzu TOC-V CSH TOC analyzer using a high-temperature combustion method.

\subsection{Optical properties analyses}

UV-Vis absorbance scans for filtered samples were recorded on a Varian Cary 50 Bio spectrophotometer and recorded over a range of 200 to $800 \mathrm{~nm}$ in a $1 \mathrm{~cm}$ quartz cuvette. The optical proxy for molecular weight (slope ratio; $S_{\mathrm{R}}$ ) and the fluorescence index (FI) were determined as described in the literature (Helms et al., 2008; McKnight et al., 2001, respectively). Here, the $S_{\mathrm{R}}$ value is inversely proportional to the DOM molecular weight, and FI values determined by the ratio of $470 / 520 \mathrm{~nm}$ emission at 370 excitation (Jaffé et al., 2008) can range between 1.4 and 1.9 for soil/terrestrial higher plant and microbial DOM sources, respectively. A blank scan (Milli-Q water) was subtracted from each sample spectrum and spectra were baseline normalized using the 
Table 1. DOC and optical properties of the six bulk water samples collected for SPE-DOM.

\begin{tabular}{|c|c|c|c|c|c|c|c|c|c|c|c|c|c|c|c|}
\hline & Sample & $\begin{array}{r}\text { DOC } \\
(\mathrm{ppm})\end{array}$ & $\mathrm{SUV}_{254}$ & $\mathrm{Abs}_{254}$ & $S_{\mathrm{R}}$ & FI & $\begin{array}{r}\text { TFI } \\
(\mathrm{QSU})\end{array}$ & $\% \mathrm{C} 1$ & $\% \mathrm{C} 2$ & $\% \mathrm{C} 3$ & $\% \mathrm{C} 4$ & $\% \mathrm{C} 5$ & $\%$ C6 & $\% \mathrm{C} 7$ & $\% \mathrm{C} 8$ \\
\hline 1 & FCE-L & 28.57 & 2.95 & 0.844 & 0.95 & 1.34 & 968.34 & $28 \%$ & $9 \%$ & $23 \%$ & $12 \%$ & $14 \%$ & $3 \%$ & $6 \%$ & $4 \%$ \\
\hline 2 & FCE-S & 9.67 & 2.72 & 0.263 & 0.98 & 1.44 & 360.11 & $34 \%$ & $3 \%$ & $15 \%$ & $13 \%$ & $15 \%$ & $10 \%$ & $5 \%$ & $5 \%$ \\
\hline 3 & OKA-L & 6.33 & 3.19 & 0.202 & 0.91 & 1.36 & 180.99 & $35 \%$ & $1 \%$ & $19 \%$ & $11 \%$ & $17 \%$ & $7 \%$ & $7 \%$ & $3 \%$ \\
\hline 4 & OKA-S & 9.87 & 2.98 & 0.294 & 0.97 & 1.33 & 158.16 & $31 \%$ & $3 \%$ & $20 \%$ & $11 \%$ & $16 \%$ & $5 \%$ & $10 \%$ & $4 \%$ \\
\hline 5 & PAN-L & 5.82 & 5.11 & 0.297 & 0.92 & 1.41 & 267.59 & $34 \%$ & $2 \%$ & $16 \%$ & $10 \%$ & $15 \%$ & $8 \%$ & $10 \%$ & $5 \%$ \\
\hline 6 & PAN-S & 6.60 & 4.49 & 0.296 & 0.91 & 1.39 & 270.05 & $37 \%$ & $0 \%$ & $20 \%$ & $11 \%$ & $16 \%$ & $7 \%$ & $6 \%$ & $3 \%$ \\
\hline
\end{tabular}

$\% \mathrm{CX}=$ relative abundance of PARAFAC component $\mathrm{X}$

$\mathrm{L}$ and $\mathrm{S}$ indicate long or short hydroperiod.
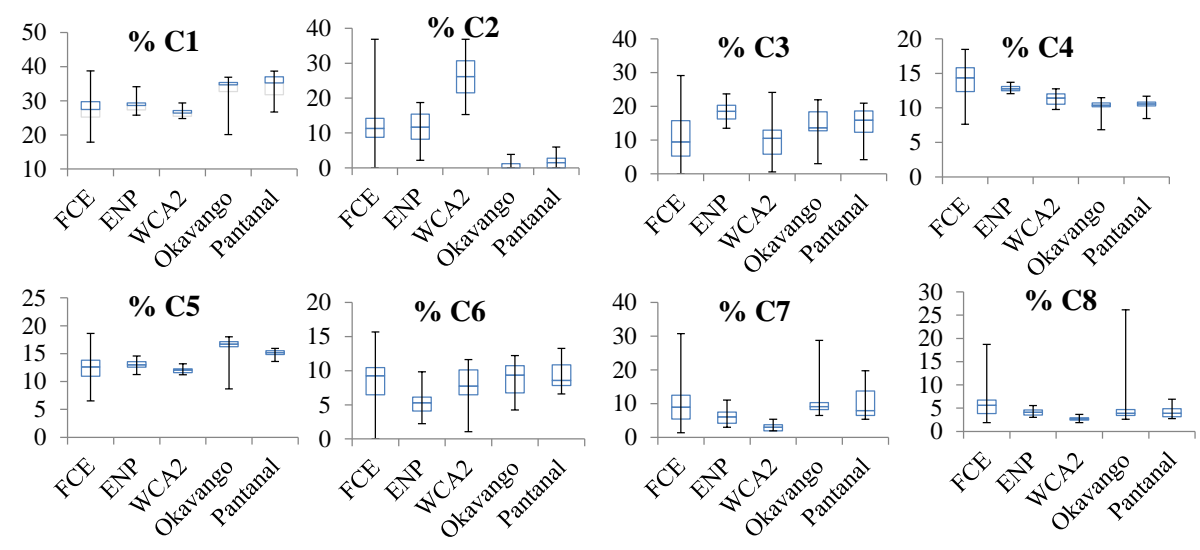

Figure 1. Box plots of the relative abundance (\%) of PARAFAC components for the Florida coastal Everglades (FCE), Okavango (OKA) and Pantanal (PAN) regions. Top of the blue box represents the 75th percentile, middle of the blue box is the median, lower edge of blue box is the 25th percentile, top of the black bar is the maximum value, and bottom of the black bar is the minimum value. ENP $=$ Everglades National Park; WCA2 = Everglades Water Conservation Area 2.

average absorbance between $700-800 \mathrm{~nm}$. The absorbance at $254 \mathrm{~nm}\left(A_{254}\right)$ was also determined and normalized to DOC to obtain specific UV absorbance values $\left(\mathrm{SUVA}_{254}\right.$; Weishaar et al., 2003). Samples were analyzed for fluorescence within 2 weeks of collection. Fluorescence EEMs were collected on a Horiba Jobin Yvon SPEX Fluoromax-3 spectrofluorometer using the methods of Maie et al. (2006) and Yamashita et al. (2010). Briefly, EEMs were collected over an excitation wavelength $\left(\lambda_{\text {ex }}\right)$ range of $240-455 \mathrm{~nm}$ with an increment of $5 \mathrm{~nm}$ and an emission range of $\lambda_{\mathrm{ex}}+10 \mathrm{~nm}$ to $\lambda_{\text {ex }}+250 \mathrm{~nm}$ with an increment of $2 \mathrm{~nm}$ in a $1 \mathrm{~cm}$ quartz cuvette. The excitation and emission slit widths were set to 5.7 and $2 \mathrm{~nm}$, respectively. Fluorescence scans were collected in signal/reference ratio mode with an integration time of $0.25 \mathrm{~s}$ and reported in quinine sulfate units (QSU). EEMs were corrected for instruments optics and inner-filter effects according to Ohno (2002) and Raman normalized and blank subtracted using Matlab v2009a software. EEMs were modeled using Matlab v2009a and fit to an eight-component PARAFAC model described in Chen et al. (2010) and Yamashita et al. (2010) that was comprised of FCE samples only. Results from optical property determinations are shown in Table 1 and Fig. 1.

\subsection{Nuclear magnetic resonance spectroscopy (NMR)}

${ }^{1} \mathrm{H}$ NMR detected spectra of methanolic DOM extracts were acquired with a Bruker Avance NMR spectrometer at 500.13 (1-D NMR only)/800.13 MHz $\left(B_{0}=11.7 / 18.7 \mathrm{~T}\right)$ at $283 \mathrm{~K}$ from a few milligrams of solid obtained by evaporation of original methanol- $\mathrm{h}_{4}$ solution, dissolved in approx. $130 \mu \mathrm{L} \mathrm{CD} \mathrm{CD}_{3} \mathrm{OD}$ (Merck. $99.95 \%{ }^{2} \mathrm{H}$ ) solution with a $5 \mathrm{~mm}$ z-gradient ${ }^{1} \mathrm{H} /{ }^{13} \mathrm{C} /{ }^{15} \mathrm{~N} /{ }^{31} \mathrm{P}$ QCI cryogenic probe $\left(90^{\circ}\right.$ excitation pulses: ${ }^{13} \mathrm{C} \sim{ }^{1} \mathrm{H} \sim 10 \mu \mathrm{s}$ ) in sealed $2.5 \mathrm{~mm}$ Bruker MATCH tubes. ${ }^{1} \mathrm{H}$ NMR spectral information is shown in Table 2 and Fig. 2 and Figs. S1 and S2 in the Supplement. ${ }^{13} \mathrm{C}$ NMR spectra were acquired with a Bruker Avance NMR spectrometer at $500.13 / 800.13 \mathrm{MHz}\left(B_{0}=11.7 / 18.7 T\right)$ at $283 \mathrm{~K}$ from a few $\mathrm{mg}$ of solid obtained by evaporation of original methanol- $\mathrm{h}_{4}$ solution ( $1 \mathrm{~s}$ acquisition time, 14 or 19s relaxation delay; Table S1; Fig. S3 in the Supplement). 1-D ${ }^{1} \mathrm{H}$ NMR spectra were recorded with a spinecho sequence $(10 \mu$ s delay) to allow for high-Q probe ringdown, and classical presaturation to attenuate residual wa- 
Table 2. ${ }^{1} \mathrm{H}$ NMR section integral for key substructures of natural organic matter (SPE-DOM) as computed from $0.001{ }^{1} \mathrm{H}$ NMR bucket NMR integrals (see Fig. S2); owing to distribution of HSQC cross-peaks, the distinction between aromatic and olefinic molecules was placed at $\delta_{\mathrm{H}}=6.5 \mathrm{ppm}$ (see Fig. 4).

\begin{tabular}{lccccc}
\hline$\delta\left({ }^{1} \mathrm{H}\right)[\mathrm{ppm}]$ & $10.0-6.50$ & $6.5-5.3$ & $4.9-3.1$ & $3.1-1.9$ & $1.9-0.0$ \\
\hline Key substructures & $\mathbf{H}_{\mathbf{a r}}$ & $\mathrm{C}=\mathrm{CH}, \mathrm{O}_{2} \mathrm{CH}$ & OCH & XCCH & CCCH \\
OKA-L & 7.2 & 3.0 & 29.6 & 26.9 & 33.4 \\
OKA-S & 7.2 & 3.0 & 31.0 & 26.5 & 32.3 \\
PAN-L & 7.5 & 2.9 & 28.1 & 28.5 & 33.1 \\
PAN-S & 7.2 & 2.7 & 29.7 & 27.9 & 32.4 \\
FCE-L & 5.5 & 2.4 & 27.9 & 30.5 & 33.7 \\
FCE-S & 5.3 & 2.1 & 29.3 & 28.9 & 34.4 \\
\hline
\end{tabular}

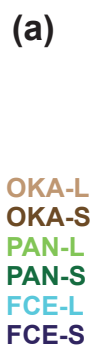

(b)

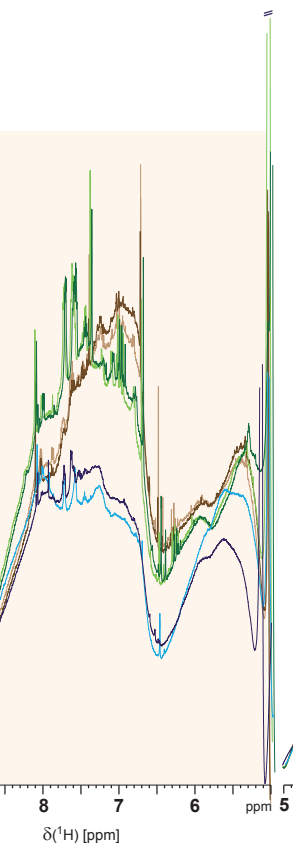

(c)

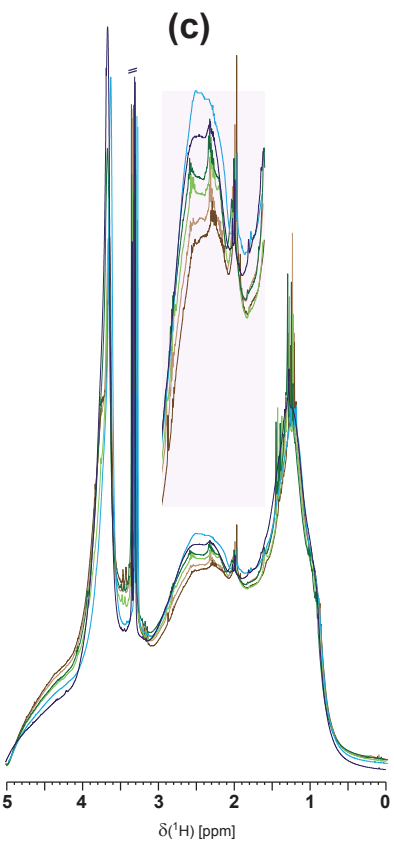

Figure 2. ${ }^{1} \mathrm{H}$ NMR spectra of six wetland SPE-DOM $\left(500 \mathrm{MHz} ; \mathrm{CD}_{3} \mathrm{OD}\right)$; overlay: intensities are normalized to total NMR resonance area in the entire chemical shift range shown $\left(\delta_{\mathrm{H}}=0-10 \mathrm{ppm}\right)$, with exclusion of residual water and methanol NMR resonances (Fig. S1). (a) Entire NMR spectrum $\left(\delta_{\mathrm{H}}=0-10 \mathrm{ppm}\right)$, with section of unsaturated protons $\left(\delta_{\mathrm{H}}=5-10 \mathrm{ppm}\right)$, highlighted in orange; (b) section of unsaturated protons $\left(\delta_{\mathrm{H}}=5-10 \mathrm{ppm}\right)$; (c) section of aliphatic protons $\left(\delta_{\mathrm{H}}=0-5 \mathrm{ppm}\right)$; highlighted in purple: vertical expansion of functionalized aliphatic compounds, associated also with CRAM (carboxyl-rich alicyclic compounds).

ter present "noesyprld", typically 512-2048 scans (5 s acquisition time, $5 \mathrm{~s}$ relaxation delay, $1 \mathrm{~ms}$ mixing time; $1 \mathrm{~Hz}$ exponential line broadening). A phase-sensitive, gradientenhanced TOCSY NMR spectrum with solvent suppression (dipsi2etgpsi19) was acquired for an acquisition time of $1 \mathrm{~s}$, a mixing time of $70 \mathrm{~ms}$, and a relaxation delay of $3 \mathrm{~s}$. The one-bond coupling constant ${ }^{1} \mathrm{~J}(\mathrm{CH})$ used in 2-D ${ }^{1} \mathrm{H},{ }^{13} \mathrm{C}$ DEPT-HSQC spectra (hsqcedetgpsisp 2.2) was set to $145 \mathrm{~Hz}$; other conditions: ${ }^{13} \mathrm{C} 90^{\circ}$ decoupling pulse, GARP $(70 \mu \mathrm{s}) ; 50 \mathrm{kHz}$ WURST $180^{\circ}{ }^{13} \mathrm{C}$ inversion pulse (Wideband, Uniform, Rate and Smooth Truncation; $1.2 \mathrm{~ms}$ ); F2 $\left({ }^{1} \mathrm{H}\right)$ : spectral width of $5981 \mathrm{~Hz}(11.96 \mathrm{ppm}) ; 1.25 \mathrm{~s}$ relaxation delay; F1 $\left({ }^{13} \mathrm{C}\right): \mathrm{SW}=17607 \mathrm{~Hz}(140 \mathrm{ppm})$. HSQC- derived NMR spectra were computed to a $4096 \times 512$ matrix. Gradient- ( $1 \mathrm{~ms}$ length, $450 \mu$ recovery) and sensitivityenhanced sequences were used for all 2-D NMR spectra. Absolute value JRES/COSY and phase-sensitive echoantiecho TOCSY spectra (with solvent suppression: jresgpprqf, cosygpph19, dipsi2etgpsi19) used a spectral width of $9615.4 \mathrm{~Hz}-$ JRES $(\mathrm{F} 1)=50 \mathrm{~Hz}-$ and were computed to a $16384 \times 2048$ matrix - JRES $(\mathrm{F} 1)=128$. The similarity of ${ }^{1} \mathrm{H}$ NMR spectra was computed from $0.01 \mathrm{ppm}$ section integrals in the range $\delta_{\mathrm{H}}=0.5-9.5 \mathrm{ppm}$, with exclusion of methanol and residual water (Bruker AMIX software, version 3.9.4.) with Hierarchical Cluster Explorer (HCE); similarity vs. distance metrics used Pearson correlation coeffi- 
Table 3. Counts of mass peaks in wetland SPE-DOM as computed from negative electrospray (ESI) $12 \mathrm{~T}$ FTICR mass spectra for singly charged ions.

\begin{tabular}{|c|c|c|c|c|c|c|}
\hline $\begin{array}{l}\text { Members of } \\
\text { molecular series }\end{array}$ & OKA-L & OKA-S & PAN-L & PAN-S & FCE-L & FCE-S \\
\hline CHO compounds & $1581(57.6 \%)$ & $1772(60.0 \%)$ & $1711(58.8 \%)$ & $1844(56.5 \%)$ & $1400(37.2 \%)$ & $1201(32.2 \%)$ \\
\hline CHOS compounds & $266(9.7 \%)$ & $207(6.8 \%)$ & $211(7.3 \%)$ & $260(8.0 \%)$ & $1127(29.9 \%)$ & $1400(37.5 \%)$ \\
\hline CHNO compounds & $893(32.5 \%)$ & $1075(35.2 \%)$ & $984(33.8 \%)$ & $1151(35.3 \%)$ & $864(22.9 \%)$ & $761(20.4 \%)$ \\
\hline $\begin{array}{l}\text { CHNOS } \\
\text { compounds }\end{array}$ & $5(0.2 \%)$ & $3(0.1 \%)$ & $5(0.2 \%)$ & $8(0.3 \%)$ & $375(10.0 \%)$ & $372(10.0 \%)$ \\
\hline $\begin{array}{l}\text { Total number of } \\
\text { assigned mass } \\
\text { peaks }\end{array}$ & 2745 & 3057 & 2911 & 3263 & 3766 & 3734 \\
\hline $\begin{array}{l}\text { Total number of } \\
\text { mass peaks }\end{array}$ & 9830 & 10315 & 10588 & 10818 & 11692 & 10989 \\
\hline $\begin{array}{l}\text { Percentage of mass } \\
\text { peaks attributed to } \\
\text { CHO, CHOS, } \\
\text { CHNO and } \\
\text { CHNOS } \\
\text { compositions }\end{array}$ & $28 \%$ & $30 \%$ & $27.5 \%$ & $30 \%$ & $32 \%$ & $34 \%$ \\
\hline Average H [\%] & 40.66 & 41.41 & 39.34 & 39.54 & 40.82 & 41.14 \\
\hline Average C [\%] & 38.12 & 37.75 & 38.77 & 38.73 & 37.14 & 39.39 \\
\hline Average O [\%] & 20.69 & 20.33 & 21.45 & 21.27 & 21.06 & 18.36 \\
\hline Average N [\%] & 0.38 & 0.38 & 0.40 & 0.42 & 0.37 & 0.27 \\
\hline Average S [\%] & 0.16 & 0.13 & 0.04 & 0.04 & 0.61 & 0.83 \\
\hline $\begin{array}{l}\text { Computed average } \\
\mathrm{H} / \mathrm{C} \text { ratio }\end{array}$ & 1.06 & 1.09 & 1.01 & 1.02 & 1.09 & 1.04 \\
\hline $\begin{array}{l}\text { Computed average } \\
\mathrm{O} / \mathrm{C} \text { ratio }\end{array}$ & 0.54 & 0.53 & 0.55 & 0.54 & 0.56 & 0.46 \\
\hline $\begin{array}{l}\text { Computed average } \\
\mathrm{C} / \mathrm{N} \text { ratio }\end{array}$ & 101.2 & 100.6 & 97.4 & 93.2 & 99.7 & 145.5 \\
\hline $\begin{array}{l}\text { Computed average } \\
\mathrm{C} / \mathrm{S} \text { ratio }\end{array}$ & 246 & 285 & 877 & 885 & 60.5 & 47.3 \\
\hline $\begin{array}{l}\text { Mass-weighted } \\
\text { average }\end{array}$ & 378.2 & 375.2 & 388.8 & 386.0 & 386.7 & 402.2 \\
\hline
\end{tabular}

cients; minimum similarity values are provided in Fig. S2a. Other NMR acquisition conditions are given in Table $\mathrm{S} 2$.

\subsection{FTICR mass spectrometry}

Ultrahigh-resolution Fourier transform ion cyclotron mass spectra were acquired using a $12 \mathrm{~T}$ Bruker Solarix mass spectrometer (Bruker Daltonics, Bremen, Germany) fitted with an electrospray ionization source in negative mode. Diluted SPE-DOM $\left(5 \mu \mathrm{g} \mathrm{mL}^{-1}\right.$ in methanol) were injected into the electrospray source using a micro-liter pump at a flow rate of $120 \mu \mathrm{Lh}^{-1}$ with a nebulizer gas pressure of $138 \mathrm{kPa}$ and a drying gas pressure of $103 \mathrm{kPa}$. A source heater temperature of $200^{\circ} \mathrm{C}$ was maintained to ensure rapid desolvatation in the ionized droplets. Spectra were first externally calibrated on clusters of arginine in $\mathrm{MeOH}\left(0.57 \mu \mathrm{mol} \mathrm{L}^{-1}\right)$ and internal calibration was systematically done in the presence of natural organic matter reaching accuracy values lower than $500 \mathrm{ppb}$. The spectra were acquired with a time domain of 4 megawords and 1000 scans were accumulated for each spectrum. Calculation of elemental formulas for each peak 
was done in a batch mode by an in-house written software tool. The generated formulae were validated by setting sensible chemical constraints $-\mathrm{N}$ rule, $\mathrm{O} / \mathrm{C}$ ratio $\leq 1, \mathrm{H} / \mathrm{C}$ ratio $\leq 2 \mathrm{n}+2\left(\mathrm{C}_{n} \mathrm{H}_{2 n+2}\right)$. Element counts: $\mathrm{C} \leq 100, \mathrm{H} \leq 200$, $\mathrm{O} \leq 80, \mathrm{~N} \leq 3, \mathrm{~S} \leq 2, \mathrm{P} \leq 1$ and mass accuracy window (set at $\pm 0.5 \mathrm{ppm})$. Final formulae were generated and categorized into groups containing $\mathrm{CHO}$, CHNO, CHOS or CHNOS molecular compositions which were used to reconstruct the group-selective mass spectra (Schmitt-Kopplin et al., 2010). The computed average values for $\mathrm{H}, \mathrm{C}, \mathrm{N}, \mathrm{O}$ and $\mathrm{S}$ (atom \%) and the $\mathrm{H} / \mathrm{C}$ and $\mathrm{O} / \mathrm{C}$ ratios were based upon intensityweighted averages of mass peaks with assigned molecular formulae, which comprised $\sim 30 \%$ of observed mass peaks. FTICR mass spectrometry data are summarized in Table 3.

\section{Results and discussion}

\subsection{Optical properties}

Optical properties consisting of $A_{254}, \mathrm{SUV} A_{254}$, FI, $S_{\mathrm{R}}$ and EEM-PARAFAC for the six samples for SPE-DOM analysis are presented in Table 1. Although large differences in DOC and $A_{254}$ were observed for the different samples (DOC range of 5.8 to $28.6 \mathrm{ppm} ; A_{254}$ from 0.202 to 0.844 ) some of the qualitative optical parameters such as the $S_{\mathrm{R}}$ values (range 0.91 to 0.98 ) and the FI values (range 1.30 to 1.44) all fell into a relatively narrow range. In contrast, the SUV $A_{254}$ values covered a larger range from 2.72 to 5.11 . A linear correlation was observed between the DOC and the $A_{254}\left(r^{2}=0.95\right)$.

$S_{\mathrm{R}}$ and FI values were quite similar for all sample pairs and among samples, suggesting that the molecular weight distribution and the soil/higher plant vs. microbial contributions were quite similar among these samples, or that the mineralization of wetland DOM leads to similar compositional features for systems with different organic matter sources. Detailed molecular characterizations of DOM in headwater streams from different climatic regions (biomes) have been reported to exhibit remarkably similar bulk characteristics, although site-specific features were also identified in each case (Jaffé et al., 2012). However, in the case of the SUV $A_{254}$, some clear compositional variations between different wetland DOM became apparent, where the samples from the more strongly soil-OM (or peat) influenced, longhydroperiod sites, featured higher SUV $A_{254}$ values compared to those with larger microbial and emergent/aquatic plant influenced, short-hydroperiod sites. Indeed, SUV $A_{254}$ showed higher values for the peat-based FCE-L compared to the marl-based FCE-S, the Paraguay River sample PANL compared to the wetland channel PAN-S, and in the seasonally flooded Boro River floodplain OKA-L compared to the occasional floodplain OKA-S. Although the differences in FI for the PAN samples were not significant, FI values for the other sites were expectedly inversely correlated to SUVA $_{254}$ (Jaffé et al., 2008).

The application of the FCE PARAFAC model to the OKA and PAN samples resulted in an excellent fit leaving no significant residues and was properly validated. The application of the FCE PARAFAC model to assess fluorescence characteristics of DOM from other wetlands was previously reported for the Okavango Delta (Cawley et al., 2012). In addition, the distribution of the EEM-PARAFAC components was also surprisingly similar among the six samples with $\mathrm{C} 1$ being dominant, followed by $\mathrm{C} 3>\mathrm{C} 5>\mathrm{C} 4>\mathrm{C} 6$ and $\mathrm{C} 7$ and with $\mathrm{C} 2$ and $\mathrm{C} 8$ showing the lowest relative abundance. This trend is consistent with previous reports for the greater Everglades ecosystem (Yamashita et al., 2010; Chen et al., 2013). EEM-PARAFAC results for the three wetlands are shown in Fig. 1. The data for FCE are presented as two separate subgroups representing Everglades National Park (ENP) sites and the Water Conservation Area 2 (WCA2), an area located north of the ENP boundary where water resources are heavily managed and agricultural runoff is significant (Yamashita et al., 2010). In general terms, no significant differences were observed in the PARAFAC component distributions between FCE, OKA and PAN, and the only difference of significance was the relative abundance of the C2 PARAFAC component which was higher in the WCA2 compared to all other study regions. In agreement with the above, comparing the EEMPARAFAC distributions between and among the six stations, and amongst the larger data sets of collected surface water samples (Table 1; Fig. 1), no statistically significant differences were observed, although the range in values was large. Component $\mathrm{C} 2$ has been suggested to be photo-chemically stable or possibly a photo-degradation product (Chen et al., 2010; Cawley et al., 2012; Chen and Jaffé, 2014) and has also been identified as derived from the oxidation of soil OM, being exported from the Everglades Agricultural Area (EAA; located to the north of the WCA; Yamashita et al., 2010). As such it is not surprising that the levels for $\mathrm{C} 2$ are enriched in waters from the WCA2, which receives significant canal inputs from the EAA. In the other wetlands and at freshwater marshes in more distant regions of the Everglades, C2 is only a relatively minor component of the DOM fluorescence signal. However, the most interesting aspect of this comparison is that the FCE-based PARAFAC model provided a perfect fit for both the OKA and PAN samples, suggesting that the overall fluorescent properties of the DOM in the three wetlands are quite similar.

\subsection{NMR study}

\subsection{1 ${ }^{1}$ H NMR spectra}

High-field $(800 \mathrm{MHz})$ NMR spectra with cryogenic detection performed on six samples (paired long- and shorthydroperiod sites from each wetland) revealed an exceptional coverage and chemical description of wetland organic 
proton and carbon chemical environments. The ${ }^{1} \mathrm{H}$ NMR spectra of wetland DOM acquired with solvent suppression showed the prevalence of rather smooth bulk signal envelopes reflecting intrinsic averaging from massive signal overlap with a considerable variance in abundance for all major chemical environments. In addition, rather minor superimposed sharp individual NMR resonances were indicative of biological signatures and occurred in the order PAN > OKA > FCE (Figs. 2 and S1). From higher to lower field (from right to left), abundant (a) aliphatics, (b) "acetateanalogues", (c) carboxyl-rich alicyclic molecules (CRAM), (d) "carbohydrate-like" and methoxy, (e) olefinic, and (f) aromatic NMR resonances showed well-visible and rather broad maxima (letters given according to Fig. S1).

Superimposed small NMR resonances indicative of comparatively abundant biological and biogeochemical molecules were most significant in the aromatic section (f), well noticeable in sections (e) and (a), and of continual lesser occurrence in the order $c>b>d$ (Fig. S1). The area-normalized ${ }^{1} \mathrm{H}$ NMR spectra of the six DOM samples (Fig. 2) showed more variance than their respective ${ }^{1} \mathrm{H}$ NMR section integrals (Table 2 ), a plausible consequence of intrinsic averaging across sizable chemical shift windows (Hertkorn et al., 2007). One-dimensional ${ }^{1} \mathrm{H}$ NMR spectra of wetland SPE-DOM revealed clear distinctions according to sample location, with pronounced congruence between the three pairs of samples (Fig. S1). Within sample pairs, internal differences mainly referred to intensity variations (denoting variable abundance) rather than to alterations of NMR resonances positioning (denoting molecular diversity). The relative disparity was largest between both FCE-L and FCE-S whereas PAN and OKA samples were more alike among themselves (Fig. S2a-d). Otherwise, molecular divergence was most obvious in the case of unsaturated protons $\left(\delta_{\mathrm{H}}>5 \mathrm{ppm}\right)$. Subtle relative changes in composition between pairs of samples were readily visualized by superposition NMR spectra in which the relative NMR section integrals of each aromatic and aliphatic substructure had been normalized to $100 \%$ (Fig. S2e-g).

The larger discrimination observed between ${ }^{1} \mathrm{H}$ NMR spectra of DOM from different wetlands in comparison with the intrinsic variance among DOM within each wetland already suggested the presence of an individual molecular signature, characteristic of each particular wetland. Table 2 shows the respective ${ }^{1} \mathrm{H}$ NMR section integrals for the six samples under study. Generally, the OCH, XCCH and $\mathrm{CCCH}$ aliphatic chemical environments represented nearly equal contributions to make up approx. $90 \%$ of the spectrum with the $\mathrm{CCCH}$ units consistently exceeding $30 \%$. Carboxyl-rich alicyclic molecules (CRAM) and functionalized and pure aliphatics followed the order FCE $(\mathrm{L}>\mathrm{S})>\mathrm{PAN} \approx$ OKA. Molecular divergence was most noticeable in the chemical environment of unsaturated protons, where the ratio of aromatic to olefinic protons declined in the order $\mathrm{FCE}>\mathrm{PAN}>\mathrm{OKA}$. Here, $\mathbf{H}_{\mathrm{ar}}\left(\delta_{\mathrm{H}}>7 \mathrm{ppm}\right)$ and $\mathrm{C}=\mathrm{CH}, \mathrm{O}_{2} \mathrm{CH}\left(\delta_{\mathrm{H}}: 5.3-7 \mathrm{ppm}\right)$ contributed less than $5 \%$ each to the overall spectra. The differences in the NMR spectra (L-S) obtained for FCE, OKA and PAN wetland DOM were computed from area-normalized NMR spectra (Fig. S2c-d) and indicated congruent behavior for OKA and PAN SPE-DOM in the purely aliphatic section $\left(\delta_{\mathrm{H}}<3 \mathrm{ppm}\right)$, with moderate increase of $\mathrm{C}_{n} \mathrm{CH}$ groups $\left(n>1 ; \delta_{\mathrm{H}}<1.6 \mathrm{ppm}\right)$. The alterations in FCE-based aliphatics were governed by a marked increase of CRAM whereas the abundance of $\mathrm{C}_{n} \mathrm{CH}$ decreased (Fig. S2d). Interestingly, a rather concordant decline of methoxy groups (primarily methyl esters) was observed for both FCE and PAN (Fig. S2d). Polycarboxylated and PAH-derived aromatics $\left(\delta_{\mathrm{H}}>8 \mathrm{ppm}\right)$ were markedly increased in FCE-L as compared with FCE-S (see below).

For improved assessment of unsaturated protons, the respective chemical shift range was divided into several sections, comprising $\left(\mathrm{f}_{1}\right.$; letters according to Fig. $\left.\mathrm{S} 1\right)$ polycyclic and polycarboxylated aromatics as well as six-membered nitrogen heterocycles $\left(\delta_{\mathrm{H}}>8 \mathrm{ppm}\right) ;\left(\mathrm{f}_{2}\right)$ electron-withdrawing substituents (COX; Perdue et al., 2007; $\delta_{\mathrm{H}} \approx 7.3-8.0 \mathrm{ppm}$ ); $\left(\mathrm{f}_{3}\right)$ electroneutral substituents (alkyl, $\mathrm{H}, \mathrm{R} ; \delta_{\mathrm{H}} \approx 7.0-$ $7.3 \mathrm{ppm})$; $\left(\mathrm{f}_{4}\right)$ electron-donating substituents (OR, $\mathrm{OH}$, phenolics; $\left.\delta_{\mathrm{H}} \approx 6.5-7.0 \mathrm{ppm}\right) ;\left(\mathrm{e}_{1}\right)$ polarized and conjugated olefins; $\left(\delta_{\mathrm{H}} \approx 5.5-6.5 \mathrm{ppm}\right) ;\left(\mathrm{e}_{2}\right)$ isolated olefins $\left(\delta_{\mathrm{H}} \approx 5.0\right.$ $5.5 \mathrm{ppm}$ ) - this section features however contributions from anomeric protons and certain ester groups (see discussion of 2-D NMR spectra). The relative and absolute abundance of electroneutral substituted and phenolic aromatic compounds was maximal in OKA, and declined through PAN to FCE. The ratio of conjugated olefins and aromatics was similar in FCE and PAN; however, the abundance of these units was lower by ca. $30 \%$ in FCE. DOM from FCE-L showed higher proportions of isolated olefins and, possibly, anomeric positions within carbohydrates.

Within this, the FCE samples showed the lowest proportion of unsaturated protons, and among them, the shorthydroperiod site FCE-S was marginally depleted in abundance of carboxylated aromatic protons compared to the longer-hydroperiod site FCE-L, possibly due to higher light exposure at the short-hydroperiod site. Such differences among samples from PAN and OKA were not significant. Ratios of aliphatic to aromatic signals $\left(\mathrm{CCCH} / \mathbf{H}_{\mathbf{a r}}\right.$; see data in Table 2) were also highest for the FCE samples, suggesting enrichment in microbial-derived DOC (periphyton sources) compared to the PAN and OKA samples, but also featuring differences between long- and short-hydroperiod sites, where preservation of aliphatics at long-hydroperiod sites seemed to be favored for all wetlands. These differences may at first conflict with previous reports which found larger periphyton contributions to DOC at FCE-S compared to FCE-L (Chen et al., 2013) suggested to be related to drying and rewetting of periphyton mats during the dry-to-wet transition at FCE-S, and higher relative contributions of soil-derived DOM in FCE-L compared to FCE-S. Similarly, in the case 


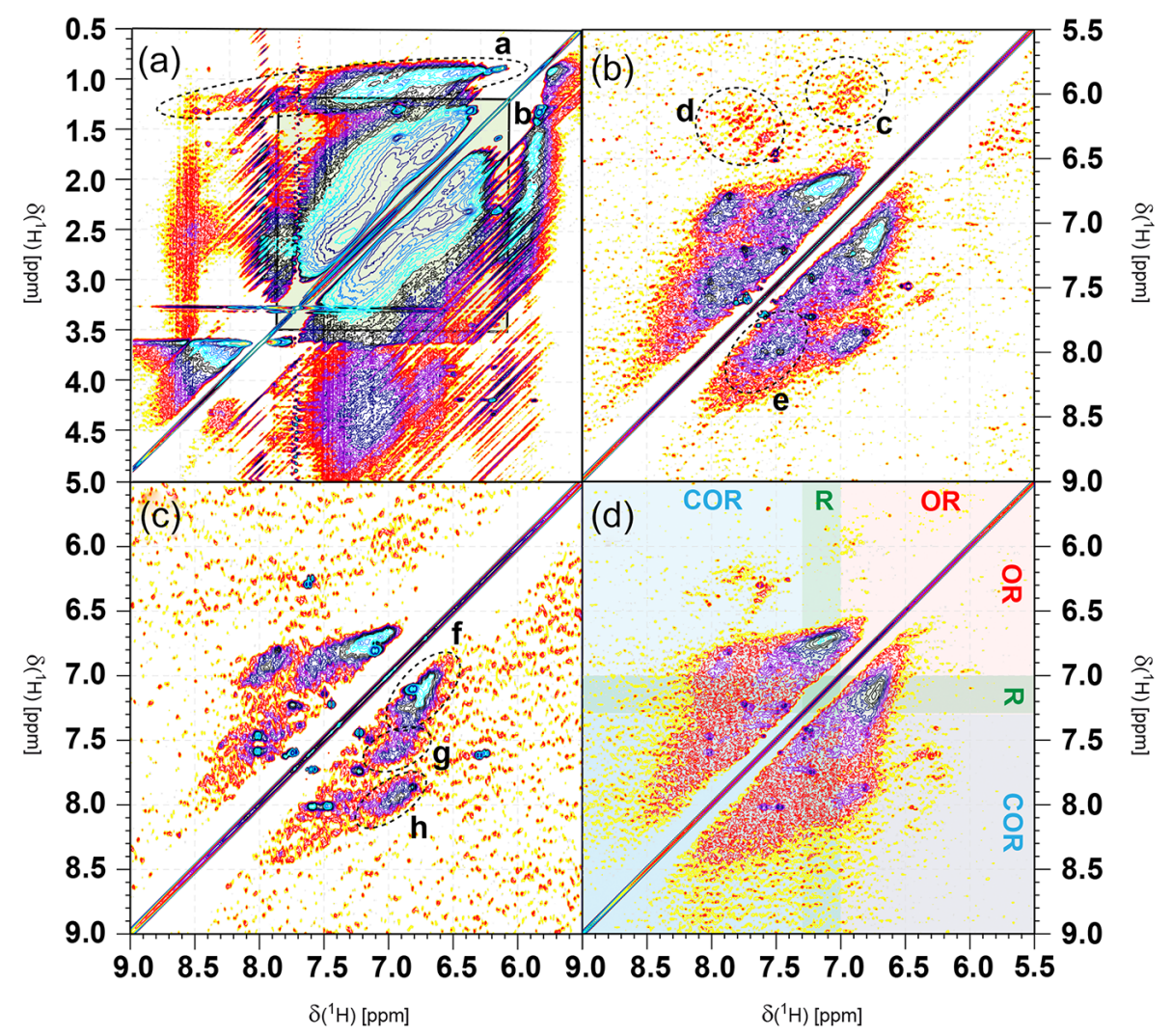

Figure 3. TOCSY NMR spectra $\left(800 \mathrm{MHz}, \mathrm{CD}_{3} \mathrm{OD}\right)$ of wetland SPE-DOM. (a) TOCSY cross-peaks between aliphatic protons $\left(\mathrm{X}-\mathrm{C}_{\mathrm{sp}} 3 \mathbf{H}-\right.$ $\mathrm{C}_{\mathrm{sp} 3} \mathrm{H}-\mathrm{X}$; X: C, O) for samples FCE-S. (b-d) TOCSY cross-peaks between unsaturated protons $\left(\mathrm{X}-\mathrm{C}_{\mathrm{sp} 2} \mathbf{H}-\mathrm{C}_{\mathrm{sp} 2} \mathbf{H}-\mathrm{X}\right.$; X: C, O) for samples FCE-S, PAN-L and OKA-S respectively. Section (a): $\mathbf{H}_{3} \mathrm{C}-\mathrm{C}_{n}-\mathrm{X}$ cross-peaks, with $n=1\left(\delta_{\mathrm{H}}>3\right)$ and $n>1\left(\delta_{\mathrm{H}}<3\right)$; where $\mathrm{X}$ is any heteroatom, likely oxygen; section (b): $-\mathrm{C}-\mathrm{CH}-\mathrm{CH}-\mathrm{C}_{n}-\mathrm{X}-$, intra-aliphatic cross-peaks; section (c): $\alpha, \beta$-unsaturated and conjugated double bonds: $\mathbf{H C}_{\text {olefin }}=\mathrm{C}_{\text {olefin }} \mathbf{H}-(\mathrm{C}=\mathrm{O})-\mathrm{X}$; section (d): polarized $\alpha, \beta$-unsaturated double bonds: $\mathbf{H C}_{\text {olefin }}=\mathrm{C}_{\mathrm{olefin}} \mathbf{H}-(\mathrm{C}=\mathrm{O})-\mathrm{X}$; section $(\mathrm{e})$ : congested fjord region in polycyclic aromatics; section (f): aromatics $\mathbf{H C}_{\text {aromatic }}-\mathrm{C}_{\text {aromatic }} \mathbf{H}$ with ortho- or/and para-oxygenated substituents (classic aromatic substitution of DOM); section (g): condensed and strongly electron-withdrawing aromatics $\mathbf{H C}_{\mathrm{aromatic}}-\mathrm{C}_{\mathrm{aromatic}} \mathbf{H}$ (multiply carboxylated, N-heterocycles); section (h): (more extended) polycyclic aromatics, polycarboxylated aromatics, N-heterocycles. (d) Sections of chemical shift for substituted aromatics as proposed by the SPARIA model (substitution patterns in aromatic rings by increment analysis): COR, electron-withdrawing substituents; R, electroneutral substituents; OR, electron-donating substituents (Perdue et al., 2007).

of the long- and short-hydroperiod comparison, the higher $\mathrm{CCCH} / \mathbf{H}_{\text {ar }}$ ratios coincided with higher SUVA values for the DOM-L samples, suggesting a difference in the relative contribution of microbial vs. higher plant/soil-derived DOM for CDOM compared to bulk DOM. CDOM, often used as a proxy for DOM, only represents a small fraction of the bulk DOC and does not include aliphatic molecules as those determined here. As such, while being a convenient and useful proxy for DOC sources, CDOM-based measurements might be less sensitive for the evaluation of compositional differences between similar samples.

Methoxy NMR resonances for FCE-S compared to FCE-L were not only more abundant, but were also shifted to lower field, indicating increased fractions of aromatic methylethers and methylesters. FCE-S undergoes periodic drying and thus exposure of soil OM (SOM) to atmospheric conditions and intense sunlight exposure of DOM after high evaporation (drying) conditions. As such, much of the SOM can be aerobically oxidized to $\mathrm{CO}_{2}$ creating marl soils. It is thus plausible that increased aerobic microbial oxidation and photoexposure at this short-hydroperiod site might enhance DOM oxidation compared to the long-hydroperiod site (FCE-L). In addition, while OKA showed an appreciable shoulder at $\delta_{\mathrm{H}}>3.75 \mathrm{ppm}$ indicative of aromatic methyl esters and ethers at, however, reduced relative abundance, this distinction was absent in both PAN and FCE (Fig. 2).

In addition to the characteristics described above, the FCE samples showed the largest proportion of aromatic compounds substituted with carbonyl derivatives (most likely carboxylic acids; $\delta_{\mathrm{H}}>7.3 \mathrm{ppm}$ ). This pattern is in accordance with the presence of dissolved black carbon (DBC) at these wetland sites, where the highest abundance was reported for the FCE samples (Ding et al., 2014a). The relatively large fraction of protons with very large down-field 


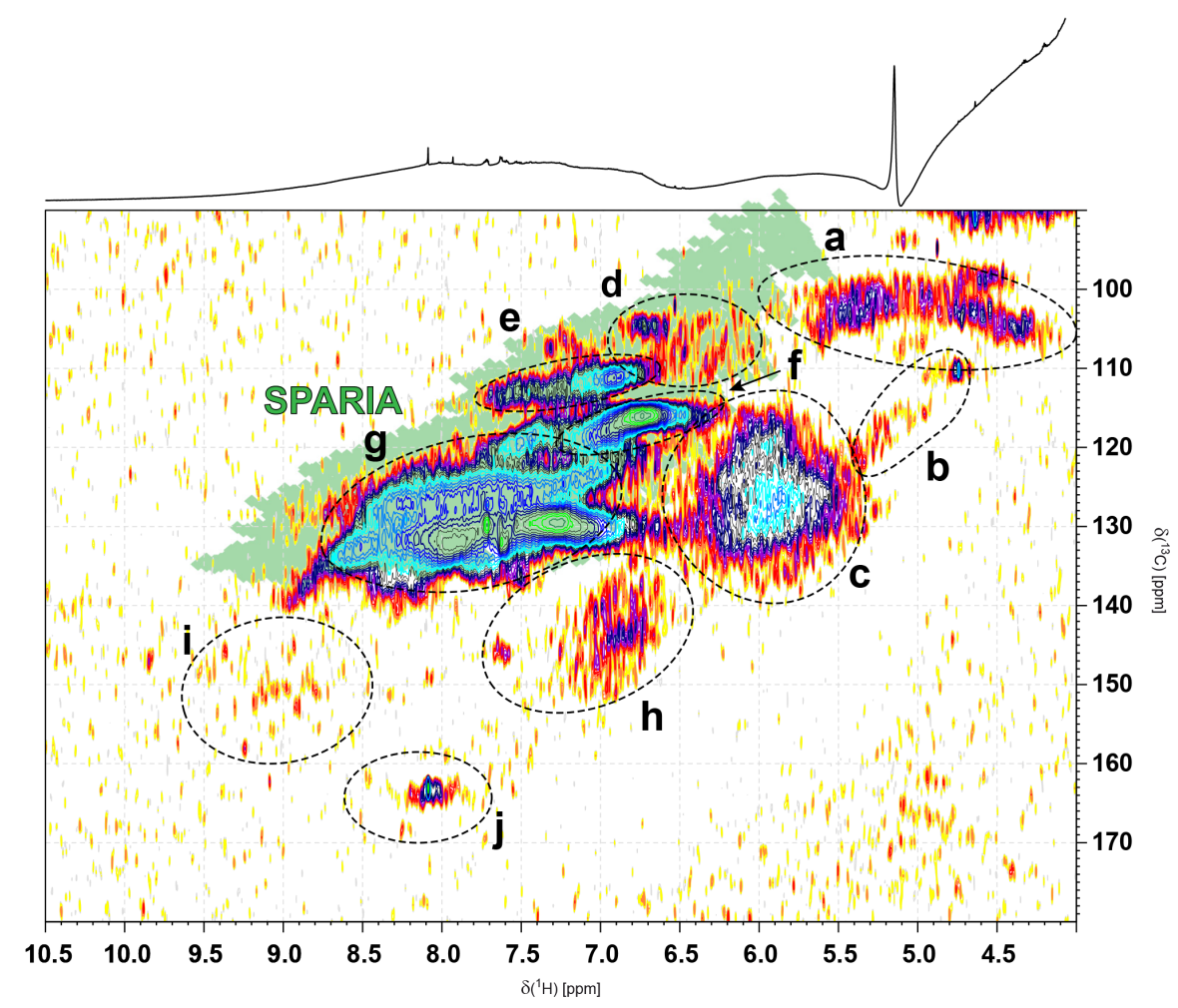

Figure 4. ${ }^{1} \mathrm{H},{ }^{13} \mathrm{C}$ HSQC NMR cross-peaks of FCE-S; section of unsaturated (olefinic and aromatic) protons $\delta_{\mathrm{H}}=4 \ldots 10.5 \mathrm{ppm}$. Assignment in analogy to South Atlantic SPE-DOM FMAX (Hertkorn et al., 2013) with key substructures denoted as follows. Section (a): anomeric $\mathrm{CH}$ in carbohydrates ( $\mathrm{sp}^{3}$-hybridized); section (b): isolated olefins; section (c): C-conjugated olefins, certain five membered $\mathrm{N}$-, Oand S-heterocycles $\left(\delta_{\mathrm{H}}<6.5 \mathrm{ppm}\right)$; section (d): multiply oxygenated aromatics including oxygen heterocycles, lignin derivatives, syringyl units (S2/6); section (e): phenols, classical oxygenated DOM aromatics, lignin derivatives, guaiacyl units (G2), certain admixture of carbonyl derivatives (likely carboxylic units), causing down-field ${ }^{1} \mathrm{H}$ NMR chemical shift $\left(\delta_{\mathrm{H}}>7.3 \mathrm{ppm}\right)$; section (f): classical DOM aromatic, lignin derivatives, guaiacyl units (G5/6), para-coumarate (C3/5); section (g): classical DOM aromatics with high proportion of carboxylated units; at $\delta_{\mathrm{H}}>8 \mathrm{ppm}$ : multiply carboxylated aromatics, classical PAH and certain six-membered nitrogen heterocycles; sterically uncongested $\mathrm{PAH}$; section (h): $\alpha, \beta$-unsaturated double bonds for $\delta_{\mathrm{C}}>140 \mathrm{ppm}$, including double bonds adjacent to aromatics: $\mathbf{C}-\mathbf{H C} \mathbf{C}_{\mathbf{o l e f i n}}=\mathbf{C}_{\mathbf{o l e f i n}} \mathbf{H}-$ $(\mathrm{C}=\mathrm{O}), \mathrm{C}_{\mathrm{ar}}-\mathrm{X}$; section (i): nitrogen heterocycles, heteroatom substituted polycyclic aromatics; section (j): certain six-membered nitrogen heterocycles, very likely with more than one nitrogen. The green area highlights the HSQC cross-peak region accessible to single benzene rings substituted by common electron-withdrawing, neutral and electron-donating common substituents of natural organic matter; SPARIA: substitution patterns in aromatic rings by increment analysis (Perdue et al., 2007).

chemical shift $\left(\delta_{\mathrm{H}}>8 \mathrm{ppm}\right)$ suggested the presence of sixmembered nitrogen heterocycles as well as that of polycyclic aromatic hydrocarbons (PAH). These units followed the abundance order PAN > OKA > FCE and could be related in part to the presence of dissolved black nitrogen (DBN; Ding et al., 2014b). However, the ratio of olefinic protons $\left(\delta_{\mathrm{H}} \sim 5.2-6.8 \mathrm{ppm}\right)$ to aromatic protons $\left(\delta_{\mathrm{H}}>6.8 \mathrm{ppm}\right.$; but see HSQC cross-peaks; Figs. 4 and S4) followed the order $\mathrm{FCE}>\mathrm{PAN} \approx \mathrm{OKA}$. The distribution of aromatic protons in OKA indicated an elevated abundance of electroneutral (alkyl, $\mathrm{H} ; \delta_{\mathrm{H}} \approx 7.0-7.3 \mathrm{ppm}$ ) and electron-donating substituents (OR, OH; $\left.\delta_{\mathrm{H}}<7.0 \mathrm{ppm}\right)$ in contrast to both FCE and PAN SPE-DOM which showed similar distribution of aromatic protons with larger proportions of electronwithdrawing substituents (COR; $\left.\delta_{\mathrm{H}}>7.3 \mathrm{ppm}\right)$ at, however, different overall abundance (Fig. 2; Table 2). In contrast, the abundance of aromatics with electroneutral $(R)$ or electrondonating substitution $(\mathrm{OR})$ with $\delta_{\mathrm{H}} \sim 7.3-6.6 \mathrm{ppm}$ (Perdue et al., 2007) followed the order OKA > PAN >> FCE (Fig. 2), likely reflecting the enhanced relative contributions of higher plant-derived DOM (in different degrees of oxidation) for the OKA and PAN compared to the FCE. In conclusion, one-dimensional ${ }^{1} \mathrm{H}$ NMR spectra showed a considerable molecular divergence of aromatic molecules in the DOM of the three wetlands, where the compositional features seemed driven by both source strengths and variations in biogeochemical processing.

Although some methoxy groups can be formed by reaction of hydroxyl groups in natural DOM and methanol during storage at ambient temperature (as SPE-DOM; Flerus et al., 2011), the HCO NMR section integral, which was found to be typically larger by $\sim 2 \%$ for the respective short- 
hydroperiod samples (Table 2), might reflect larger abundance of native methyl esters at these sites or larger abundance of DOM methanolysis products.

\subsection{2 ${ }^{13} \mathrm{C}$ NMR spectra}

${ }^{13} \mathrm{C}$ NMR spectra of wetland DOM were not overly conspicuous, with limited variance of spectra appearance and ${ }^{13} \mathrm{C}$ NMR section integrals (Fig. S3; Table S1). The abundance of non-functionalized aliphatics followed the order FCE$\mathrm{L}>\mathrm{FCE}-\mathrm{S}>\mathrm{PAN}>\mathrm{OKA}$, whereas aromaticity followed a near-reverse order FCE-L $\approx$ FCE-S $<\mathrm{OKA} \approx \mathrm{PAN}$. DOM from FCE-L showed depletion of carbohydrates and increase of lipid-like compounds (Table S1). The near-invariant abundance of carbonyl derivatives (most likely carboxylic acids) for all DOM could imply that a sizable proportion of lowfield ${ }^{1} \mathrm{H}$ NMR resonances with chemical shift $\delta_{\mathrm{H}}>7.3 \mathrm{ppm}$, which were more abundant in PAN than in the others (Fig. 2; see also aromatic TOCSY cross-peaks, Fig. 3), actually represented (substituted) PAH (with $\delta_{\mathrm{C}}<140 \mathrm{ppm}$; Hertkorn et al., 2013) rather than (poly)carboxylic aromatics (with $\delta_{\mathrm{C}} \sim 167-187$ ppm; Figs. 2 and S2; Tables 2 and S1). Computed average $\mathrm{H} / \mathrm{C}$ ratios from a basic reverse ${ }^{13} \mathrm{C}$ NMRbased mixing model ranged in the order FCE-L $>$ FCE$\mathrm{S}>\mathrm{PAN}-\mathrm{S} \approx \mathrm{OKA}-\mathrm{L}\left({ }^{13} \mathrm{C}\right.$ NMR spectra of PAN-L and OKA-S were not acquired) and primarily reflected variable content of aliphatic structures $\left(\delta_{\mathrm{C}} \sim 0-47 \mathrm{ppm}\right)$. The computed $\mathrm{O} / \mathrm{C}$ ratio was near-equal for the OKA, PAN and FCE-S samples, whereas that of FCE-L was lower by $\sim 0.07$ units. Here, a reduced abundance of oxidized aliphatic units $\left(\mathrm{HC}_{\mathrm{al}} \mathrm{O}\right)$ was primarily responsible, because phenolic and carboxylic content followed the order OKA-L $\approx$ PAN$\mathrm{S}>\mathrm{FCE}$.

\subsubsection{2-D NMR spectra}

The 2-D NMR spectra provided remarkable richness in detail and refined preliminary assignment-proposals from the onedimensional ${ }^{1} \mathrm{H}$ and ${ }^{13} \mathrm{C}$ NMR spectra. TOCSY NMR spectra (Fig. 3) revealed a wide range of methyl groups $\left(\mathbf{H}_{3} \mathrm{C}-\right.$ CH-X; X: C, O; Fig. 3a, section a); a contiguous, ill resolved cross-peak reflected a large number of intra-aliphatic correlations $\left(\mathrm{C}-\mathrm{CH}-\mathrm{C}_{n} \mathrm{H}-\mathrm{CH}-\mathrm{C} ; n=0-2\right.$; Fig. 3a, section b), and fewer cross-peaks in between oxygenated aliphatics (O$\mathrm{CH}-\mathrm{CH}-\mathrm{O}$; Fig. 3a, $\delta_{\mathrm{H}}>3.4 \mathrm{ppm}$ ). Protons bound to $\mathrm{sp}^{2}-$ hybridized carbon produced better-resolved TOCSY crosspeaks and were part of various $\alpha, \beta$-unsaturated olefins (Fig. 3b, section $\mathrm{c}-\mathrm{d}$ ), oxygenated and carbonyl (COX) derivatives of benzenes with up to three COX substituents (Fig. 3c, section $\mathrm{f}-\mathrm{h}$ ) as well as six-membered nitrogen heterocycles and more extended aromatic systems with up to several aromatic rings (Fig. $3 \mathrm{~b}$ and c, section (e) and Figs. 3d and 4). As mentioned earlier, such compounds might be related to the presence of combustion-derived compounds such as DBC and DBN (Ding et al., 2014a, b) and even dissolved black sulfur (DBS) (Hertkorn et al., 2013; see attendant discussion of FTICR mass spectra). In contrast to common five-membered heterocycles, (di)benzothiophene derivatives exhibit NMR resonances ranging from $\delta_{\mathrm{H}}$ : 7.4$8.1 \mathrm{ppm}$; corresponding HSQC cross-peaks of DBS would appear in section (g), Fig. 4.

HSQC NMR spectra of PAN and OKA did not show peculiar features which were not observable in those of both FCE samples and therefore will be not discussed here. The HSQC NMR spectra of both FCE-S and FCE-L were remarkably similar and produced near-identical overlay NMR spectra with some discernible variance in HSQC cross-peak amplitude rather than positioning (data not shown). This behavior is expected from comparison of the one-dimensional ${ }^{1} \mathrm{H}$ NMR spectra. These display differences in relative amplitude rather than positioning of NMR resonances which is indicative of variance in abundance of certain molecules rather than variance in molecular diversity (see, however, discussion of CHOS compounds present in FCE DOM as derived from FTICR mass spectrometry). About $90 \%$ of overall HSQC cross-peak integral resided in a contiguous expansive superimposed assembly of HSQC cross-peaks originating from protons bound to $\mathrm{sp}^{3}$-hybridized carbon (Fig. S4).

The resolution of these expansive aliphatic HSQC crosspeaks of FCE-S (Fig. S4) could be remarkably improved by spectral editing according to carbon multiplicity (Fig. 5). The combination of methyl- and methylene-selective DEPTHSQC NMR spectra revealed well-discriminated crosspeaks for all three types of protonated carbon; i.e., methyl, methylene and methine (Fig. 5). The chemical diversity of $\mathrm{X}-\mathrm{CH}_{3}$ groups as indicated by DEPT HSQC crosspeaks (section (a), Fig. 5) was noteworthy, and the nearGaussian distribution of $\mathrm{C}-\mathrm{CH}_{3}$ cross-peak amplitude in ${ }^{1} \mathrm{H}$ and ${ }^{13} \mathrm{C}$ NMR frequencies indicated near-maximum diversity of aliphatic chemical environments associated with these methyl groups. However, classical methyl groups terminating extensive, purely aliphatic units $\left(\delta_{\mathrm{H}}<1.0 \mathrm{ppm} ; \mathrm{CCCCH}_{3}\right.$ units) contributed less than $20 \%$ to the total $\mathbf{C C H}_{3}$ HSQC cross-peak integral. The large majority of $\mathrm{C}-\mathbf{C H}_{3}$ units was sufficiently proximate to carbonyl derivatives (i.e., most likely carboxylic acids) to let those experience down-field chemical shift anisotropy from these nearby carbonyl groups, resulting in chemical shifts ranging from $\delta_{\mathrm{H}} \sim 1.0$ to $1.7 \mathrm{ppm}$ (cross-peak a; Fig. 5). Alicyclic structures (e.g., CRAM; Hertkorn et al., 2006) facilitate clustering of chemical environments as shorter paths of chemical bonds between different substituents are realized in rings rather than in open chains. Another $\sim 20 \%$ of $\mathrm{CCH}_{3}$ in FCE was bound to olefins $\left(\mathrm{C}=\mathrm{C}-\mathbf{C H}_{3}\right.$ ), with a possible contribution of $\mathrm{S}-\mathbf{C H}_{\mathbf{3}}$ groups (section (b); Fig. 5).

The carbon-bound methylene $\left(\mathrm{C}-\mathbf{C H}_{2}-\mathrm{C}\right)$ cross-peak occupied an impressively large area down to $\delta_{\mathrm{H}} \sim 3.5 \mathrm{ppm}$, well into the proton chemical shift range commonly attributed to OCH units. The two major chemical environments discriminated were methylene more distant to $\mathrm{COX}\left(\mathrm{C}-\mathbf{C H}_{2}-\mathrm{C}_{n}-\right.$ 


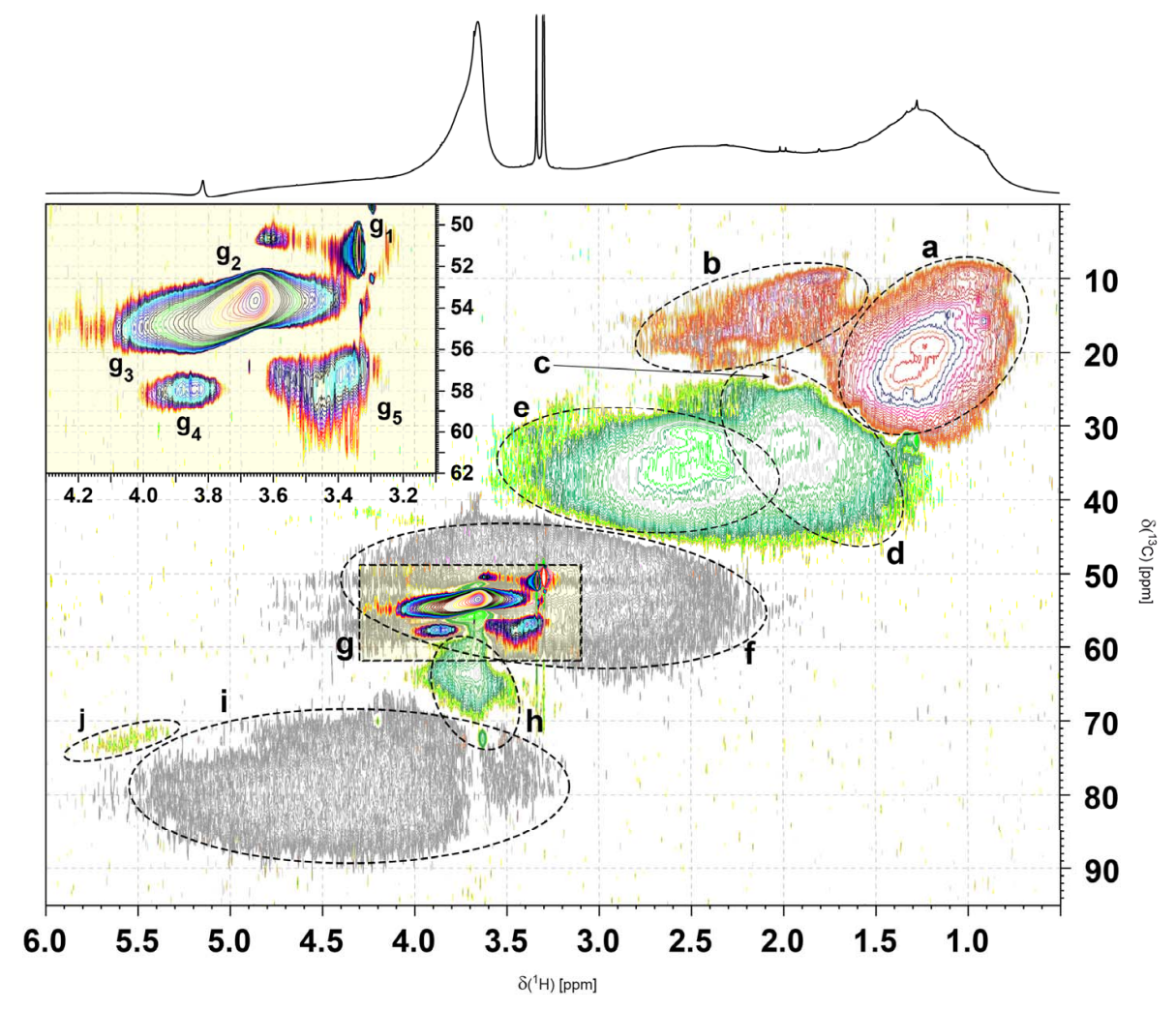

Figure 5. Methylene $\left(\mathrm{CH}_{2}\right)$ selective ${ }^{1} \mathrm{H},{ }^{13} \mathrm{C}$ DEPT - HSQC NMR spectrum of SPE-DOM FCE-S with assignment of major substructures; general colors: $\mathrm{CH}_{3}$ : red; $\mathrm{CH}_{2}$ green, and $\mathrm{CH}$ : gray; section (a): $\mathrm{C}-\mathbf{C H}_{3}$ cross-peaks; section (b): $\mathrm{C}=\mathrm{C}-\mathbf{C H}_{3}$ and $-\mathrm{SCH}$ cross-peaks; section (c): acetate $\mathbf{H}_{3} \mathbf{C}-\mathrm{C}(=\mathrm{O})-\mathrm{O}-\mathrm{C}-$; section (d): $\mathrm{C}_{2} \mathbf{C H}_{2}$ cross-peaks; section (e): $-\mathrm{C}-\mathbf{C H}_{2}-\mathrm{COOH}$ cross-peaks; section (f): $\mathrm{C}_{3} \mathbf{C H}$ cross-peaks; section $(\mathrm{g})$ : only methoxy $\left(\mathrm{OCH}_{3}\right)$ cross-peaks are shown here; see insert: section $\left(\mathrm{g}_{1}\right)$ : $\mathbf{H}_{3} \mathbf{C O H}$ (HD $\mathrm{HOD}_{2} \mathrm{CO}$ shows methine carbon); sections $\left(\mathrm{g}_{2}\right)$ and $\mathrm{g}_{3}$ : aliphatic $\left(\mathrm{g}_{2}\right)$ and aromatic $\left(\mathrm{g}_{3}\right)$ methyl esters $\mathbf{H}_{3} \mathbf{C O}-\mathrm{C}(=\mathrm{O})-\mathrm{C}-$; section $\left(\mathrm{g}_{4}\right)$ and $\left(\mathrm{g}_{5}\right)$ : aromatic $\left(\mathrm{g}_{4}\right)$ and aliphatic ( $\left.\mathrm{g}_{5}\right)$ methyl ethers $\mathbf{H}_{3} \mathbf{C O}-\mathrm{C}-\mathrm{C}$; section (f): $\mathrm{C}_{3} \mathbf{C H}$ cross-peaks; section (h): oxomethylene (OCH $\left.\mathbf{H}_{2}\right)$ cross-peaks, likely from carbohydrates; section (i): $\mathrm{OC}_{2} \mathbf{C H}$ cross-peaks; section (j): methylene bound to esters $-\mathrm{C}-\mathbf{H}_{2} \mathbf{C O}-\mathrm{C}(=\mathrm{O})-\mathrm{Z}-(\mathrm{see}$ main text).

COX, with $n \geq 1$, and $\delta_{\mathrm{H}}<2.1$ ppm cross-peak d; Fig. 5), and methylene groups directly proximate to carboxylic groups (in $\alpha$-position; i.e., $\mathbf{C}-\mathbf{C H}_{2}-\mathrm{COX}$, with $\delta_{\mathrm{H}}>2.1 \mathrm{ppm}$ crosspeak e; Fig. 5). The former shows a wider range of remote carbon substitution as indicated by the substantial spread of respective carbon chemical shifts $\left(\Delta \delta_{\mathrm{C}}: 24 / 16 \mathrm{ppm}\right.$, respectively for section (d/e) HSQC cross-peaks; Fig. 5; see also Fig. 8b in Hertkorn et al., 2013). A wide variety of aliphatic and aromatic methylesters and methylethers were also found, the latter being virtually absent in marine SPE-DOM. Here, aliphatic methyl esters were most abundant (section $\left(\mathrm{g}_{2}\right)$ in Fig. 5), aromatic methyl esters (section $\left(\mathrm{g}_{3}\right)$ in Fig. 5) and methyl ethers (section $\left(\mathrm{g}_{4}\right)$ in Fig. 5) were of similar abundance, and clearly recognizable aliphatic methyl ethers were also present (section $\left(\mathrm{g}_{5}\right)$ in Fig. 5). Oxomethylene ( $\left.\mathrm{OCH}_{2}\right)$ occurred in the form of carbohydrate side chains (section (h); Fig. 5), and a remarkable set of aliphatic oxomethylene $\left(\mathrm{OCH}_{2}\right)$ HSQC crosspeaks $\left(\delta_{\mathrm{H} / \mathrm{C}} \sim 3.4-4.0 / 58-72 \mathrm{ppm}\right.$; section (j) in Fig. 5) was present in SPE-DOM FCE-S, which does not correspond to common lignin $\beta$-aryl ether units, which resonate in this ${ }^{1} \mathrm{H}$ and ${ }^{13} \mathrm{C}$ NMR chemical shift range, but commonly comprise $\mathrm{C}_{\mathrm{ar}}-\mathbf{C H}-\mathrm{O}-$, i.e., methine substructures. Analogous oxomethine substructures are also found in phenylcoumaran, resinol and dibenzodioxocin units as well, whereas oxomethylene units with $\delta_{\mathrm{H}}>4.5$ are rare in common lignins (Ralph et al., 1998; Yelle et al., 2008; Martinez et al., 2008; Wen et al., 2013; Yuan et al., 2011). This peculiar HSQC cross-peak was discovered in FCE-S wetland SPE-DOM (section (j) HSQC cross-peak in Fig. 5) but since then has also been observed (in retrospect) with lesser distinction in other SPEDOM including those from marine sources. The singular positioning of a methylene group in the ${ }^{1} \mathrm{H}$ and ${ }^{13} \mathrm{C}$ NMR chemical shift space strongly restrains the potential diversity of its chemical environments: it has to represent a $\mathrm{OCH}_{2}$ group (methylene as defined by the phase in ${ }^{1} \mathrm{H},{ }^{13} \mathrm{C}$ DEPT HSQC NMR spectra; single oxygen because of $\delta_{C}$ : any O$\mathrm{CH}_{2}-\mathrm{O}$ environment would resonate at $\delta_{\mathrm{C}}>90 \mathrm{ppm}$ ). Similarly, common $\mathrm{O}-\mathrm{CH}_{2}-\mathrm{N}$ chemical environments would resonate at higher field than observed in both $\delta_{\mathrm{H} / \mathrm{C}}$, but cannot be excluded entirely in case of peculiar remote substitution. The most plausible substructure is $\mathrm{OCH}_{2} \mathrm{C}$; then, 
$\delta_{\mathrm{H}}$ from 5.3-5.7 ppm warrants presence of an ester group: this implies a $-\mathrm{C}-(\mathrm{C}=\mathrm{O})-\mathrm{O}-\mathrm{CH}_{2}-\mathrm{C}$ substructure. However, alkylation alone will not produce the necessary low field $\delta_{\mathrm{H}}$ observed. This leaves $-\mathrm{C}-(\mathrm{C}=\mathrm{O})-\mathrm{O}-\mathrm{CH}_{2}-\mathrm{C}=\mathrm{O}$ as a plausible group; possibly confined with a carboxylic group such as $-\mathrm{C}-(\mathrm{C}=\mathrm{O})-\mathrm{O}-\mathrm{CH}_{2}-\mathrm{COOH}$ or as an ester $\mathrm{C}-(\mathrm{C}=\mathrm{O})-\mathrm{O}-\mathrm{CH}_{2}-\mathrm{COOR}$. Both these substructures have a decent propensity to form enols with variable double-bond character $-\mathrm{C}-(\mathrm{C}=\mathrm{O})-\mathrm{O}-\mathrm{CH}=\mathrm{CH}(\mathrm{OH})_{2}$. A partial double bond character, which might be possibly controlled by mutual interactions in the complex DOM mixture of molecules, would also explain the observed spread of chemical shift in ${ }^{1} \mathrm{H}$ and ${ }^{13} \mathrm{C}$ NMR frequencies in this HSQC cross-peak even if the methylene group itself in $-\mathrm{C}-(\mathrm{C}=\mathrm{O})-\mathrm{O}-\mathrm{CH}_{2}-\mathrm{COOH}$ is four (carbon) or five (proton) bonds away from the most proximate atom position where substitution may affect its chemical shift.

Several thousands of acid and ester derivatives of acetoacetic acid $-\mathrm{H}_{3} \mathrm{C}-(\mathrm{C}=\mathrm{O})-\mathrm{O}-\mathrm{CH}_{2}-\mathrm{COOH}-$ are known in the literature. Here, many of the common esters comprise lipid substructures such as $n$-alkanes, sterane and other polyalicyclic hydrocarbons, trimethylammonium salts, among others, suggesting a natural origin of these compounds also in wetland SPE-DOM. While substructures with $-\mathrm{O}-\mathrm{CH}_{2}-\mathrm{COOZ}(\mathrm{Z}: \mathrm{H}, \mathrm{R})$ will produce distinct "oxomethylene $\left(\mathrm{OCH}_{2} \mathrm{C}\right)$ " cross-peaks in ${ }^{1} \mathrm{H},{ }^{13} \mathrm{C}$ DEPT HSQC NMR spectra (section (j) cross-peak; Fig. 5), the derivatives with $-\mathrm{O}-\mathrm{CHCH}_{n}-\mathrm{COOZ}$ substructures $(\mathrm{Z}: \mathrm{H}, \mathrm{R})$ will contribute to the ${ }^{1} \mathrm{H}$ NMR down-field section of the expansive "oxomethine $\left(\mathrm{OCHC}_{2}\right){ }^{1}{ }^{1} \mathrm{H},{ }^{13} \mathrm{C}$ DEPT HSQC cross-peak (section (i) cross-peak; Fig. 5) and will not be readily discerned owing to a larger variance in remote substitution. In addition, oxomethylene units without geminal and vicinal adjacent protons will very likely produce intense singlet NMR resonances, contributing to the enhanced visibility of HSQC cross-peaks even at rather limited relative abundance. Further evaluation of aliphatic spin systems in FCE-L provided evidence for massive aliphatic branching in $\mathrm{CCCH}$ units and of large chemical diversity of remote carboxylic substitution (Fig. S6).

TOCSY and HSQC NMR spectra demonstrated the presence of olefinic and aromatic unsaturation in all wetland SPE-DOM (Figs. 3, 4 and S5). The FCE-S showed the most informative detail of HSQC cross-peaks arising from unsaturated $\mathrm{C}_{\mathrm{sp} 2} \mathrm{H}$ groups (Fig. 4). In comparison with marine SPE-DOM (see Fig. S5 and attendant discussion), wetland SPE-DOM displayed a more restricted chemical diversity of conjugated olefins (Fig. 4) whereas all kinds of oxygenated aromatics, i.e., those substituted with electronwithdrawing (e.g., $\mathrm{COOH}$ ) and electron-donating (e.g., OR) substituents were much more abundant and chemically diverse in (all) wetland DOM (not all data shown). The latter finding is indicative of polyphenol input from vascular plants (e.g., lignin derivatives) into wetland DOM whereas aromatics in marine SPE-DOM mainly reflect marine natural prod- ucts (Fig. S5). In general, aromatic unsaturation (as deduced from proton NMR integrals; Table 2) followed the order PAN $>$ OKA $>$ FCE (Fig. S1), whereas olefinic unsaturation followed the order OKA $\sim$ PAN $>$ FCE (Fig. S1). Aliphaticto-aromatic ratios changed across the different samples with an order of FCE $>$ PAN $>$ OKA, suggesting higher relative contributions from periphyton in the FCE, whilst the PAN and OKA were more influenced by higher plant-derived organic matter including lignins. The olefinic-to-aromatic ratios (FCE-L: 0.44; FCE-S: 0.39; PAN: 0.38; OKA: 0.41) were computed from adapted ${ }^{1} \mathrm{H}$ NMR section integrals $\left(\delta_{\mathrm{H}}\right.$ : 10-6.5 ppm (aromatics)/6.5-5.0 ppm (olefins); Table 2) owing to HSQC cross-peak positioning which indicated major contribution of oxygenated aromatics $\mathbf{C}_{\mathbf{a r}} \mathrm{O}$ (at $\delta_{\mathrm{H}}: 7.0$ $6.5 \mathrm{ppm}$; Fig. 4) and showed lower values than oceanic DOC - see Hertkorn et al. (2013), who reported olefinicto-aromatic ratios in the range of 1.2 to 3.0. It is likely that this significant difference is due to the contributions of higher plant, lignin-rich carbon in the wetlands compared to marine DOM. The slightly elevated olefin content found in FCE-L may result from the contribution of periphyton-derived DOM in the Everglades (Maie et al., 2005; Chen et al., 2013; see also above). In addition, all three sites are known for frequent and seasonal fires and have been reported to contain DBC (Ding et al., 2014a) in abundances close to $10 \%$ of their DOC on a global average (Jaffé et al., 2013). However, the DBC content (as \% DOC) in the FCE was higher (as high as $20 \%$ of DOC) than for the PAN samples (13 and $14 \%$ for PAN-L and PAN-S respectively), and these were higher than the OKA samples ( 9.4 and $6.3 \%$ for OKA-L and OKA-S respectively) studied here (Jaffé et al., 2013). In addition, the presence of six-membered N-containing heterocycles in these samples might be indicative of the presence of DBN (Fig. 4i and j), which has previously been reported in the FCE (Maie et al., 2006) and proposed to consist of polyaromatic molecules containing pyrrolic-N, and multiple carboxylic substituents (Wagner et al., 2015b). With regards to the degree of oxidation of the aromatic signal, the OKA showed the highest proportion of electron-donating groups (Figs. 2, S1 and S2), such as phenols and ethers, possibly related to lignin oxidation products, while the FCE featured the highest shares of electron-withdrawing substituents (e.g., carboxyl groups) possibly associated with DBC. Although all three ecosystems have climates leading to high light exposure, the high levels of DOC in the FCE suggest some degree of self-shading, while DOC in the OKA is generally lower and the system is known for its capacity to photodegrade DOM (Cawley et al., 2012). Thus, the degree of photo-exposure of the DOM combined with combustion byproducts such as DBC, may be the driver controlling the oxidation state of the aromatic fraction. The photo-reactivity of DBC in marine environments has recently been shown (Stubbins et al., 2012) and may play a role in the lower DBC levels observed in the OKA samples. 


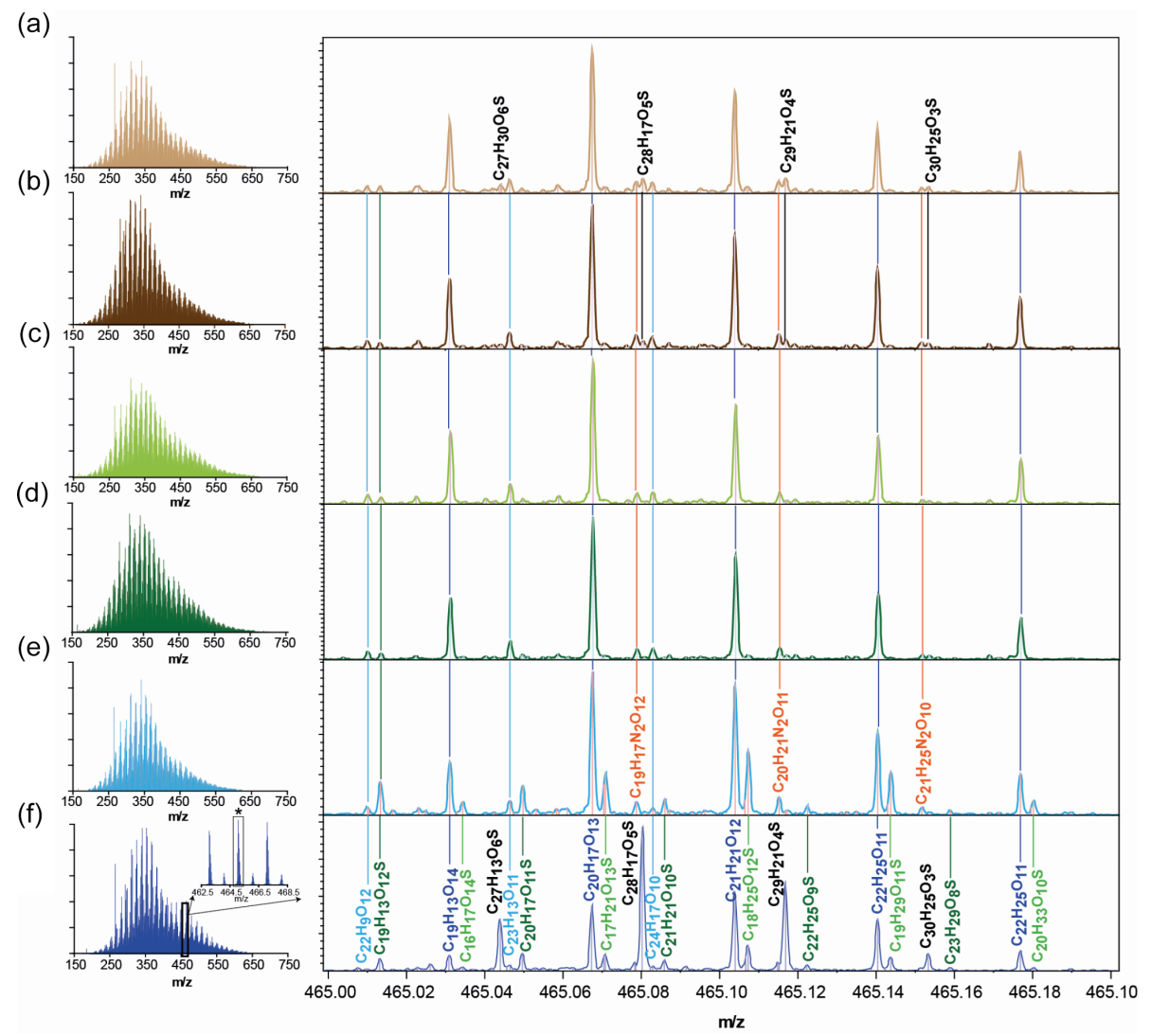

Figure 6. Left panel: negative electrospray 12 T FTICR mass spectra of Wetlands SPE-DOM (inset in Fig. 6f shows an enlarged mass view of a mass range of 6.0 Da. Right panel: expansion of the mass segment $m / z=465.00-465.20(\Delta m=0.2 \mathrm{Da}$; asterisk in inset Fig. 6f), with assignment according to CHO, CHNO, CHOS and CHNOS molecular series. (a) OKA-L; (b) OKA-S; (c) PAN-L; (d) PAN-S; (e) FCE-L; (f) FCE-S.

\subsection{FTICR mass spectrometry}

Ultrahigh-resolution Fourier transform ion cyclotron mass spectra (FTICR/MS) of DOM may provide several thousands of mass peaks for individual samples (Koch et al., 2005; Kujawinski et al., 2009), of which many hundreds were assigned here to extended CHO, CHNO, CHOS and CHNOS molecular series (Schmitt-Kopplin et al., 2010) based on the technique's excellent mass accuracy and mass resolution (Fig. 6 and Table 3). Although detailed FTICR/MS data are derived only from a few paired DOM samples (long and short hydroperiod) for each wetland, a slightly higher number of mass peaks (relative difference $<6 \%$ ) and of assigned molecular formulas (relative difference $<1 \%$ ) was observed for the FCE-L compared to the FCE-S, whereas elevated counts of mass peaks and assigned molecular compositions were found in the case of the PAN-S and OKA-S samples (relative difference $<2 \%$; Table 3). Molecular weights ranged in the order FCE-S $>$ FCE-L $\sim$ PAN $>$ OKA (Table 3). This admittedly minor molecular weight difference was not reflected in the $S_{\mathrm{R}}$ values of these samples (Table 1) which were quite similar. However, $S_{\mathrm{R}}$ only represents a molecular weight proxy for CDOM and might not be sensitive enough to reflect minor differences accurately. In general, while SPEDOM of both OKA and PAN showed near $57 \pm 2 \%$ CHO, $8 \pm 2 \% \mathrm{CHOS}, 33 \pm 2 \mathrm{CHNO}$ and $<1 \%$ CHNOS molecules, the mass spectra of FCE samples were fundamentally different compared with respect to both OKA and PAN as well as among themselves (Fig. 6; Table 3; see also Fig. 7). Sample FCE-S appeared most distinct from all other samples both with respect to total count of ions, overall mass peak distribution and with respect to molecular diversity within nominal mass ranges (Fig. 6). Here, FTICR mass spectra of both FCE samples showed the conspicuous doublets of $\mathrm{CHO} / \mathrm{CHOS}$ pairs visible at high resolution $\left(\Delta \mathrm{m}\left(\mathrm{C}_{-3} \mathrm{H}_{4} \mathrm{~S}\right)=2.4 \mathrm{mDa}\right)$ indicating a nominal exchange of $\mathrm{H}_{4} \mathrm{~S}$ against $\mathrm{C}_{3}$ (SchmittKopplin et al., 2010), whereas all other samples showed both lower abundances and diversity of CHOS compounds (Figs. 6, 7 and S7). In case of the FCE samples, CHOS and CHNOS compounds were markedly enriched at the expense of $\mathrm{CHO}$ and $\mathrm{CHNO}$ compounds. While the proportion of CHNO $(21 \pm 1 \%)$ and CHNOS $(9 \pm 1 \%)$ molecules were similar for both FCE samples, the abundance of CHOS molecules in FCE-S was elevated by more than $10 \%$, pre- 

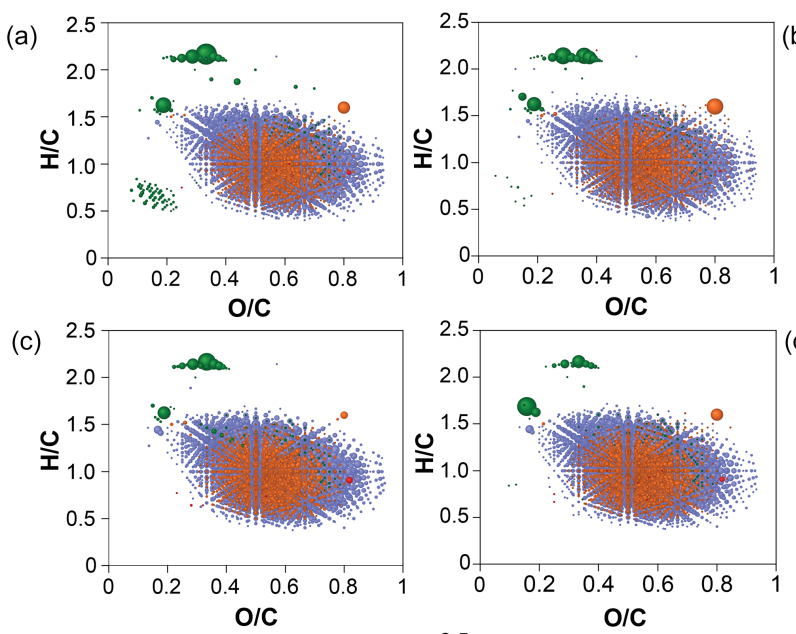

(d)
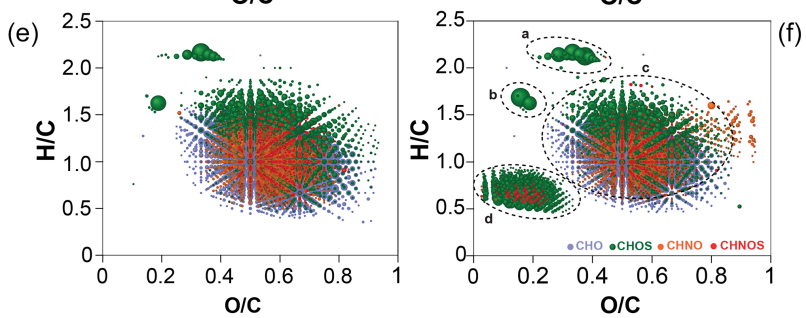

Figure 7. Van Krevelen diagrams of six wetlands SPE-DOM: (a) OKA-L, (b) OKA-S, (c) PAN-L, (d) PAN-S, (e) FCE-L, (f) FCE-S, obtained from negative electrospray $12 \mathrm{~T}$ FTICR mass spectra. Only molecular assignments bearing combinations of $\mathrm{C}$, $-\mathrm{H},-\mathrm{O},-\mathrm{N}$, and $-\mathrm{S}$ atoms are shown; color coded according to molecular series as follows: $\mathrm{CHO}$, blue; $\mathrm{CHOS}$, green; $\mathrm{CHNO}$, orange; $\mathrm{CHNOS}$, red. Bubble areas reflect the relative intensities of respective mass peaks. (f) Labels for CHOS compounds correspond to key molecules, section (a): saturated sulfolipids; section (b): unsaturated sulfolipids; section (c): common CHOS compounds in DOM, possibly sulfonated carboxylic-rich alicyclic compounds (CRAM); d: aromatic black sulfur.

dominantly at the expense of $\mathrm{CHO}$ molecules. The overall abundance of sulfur in the FCE was nearly 4-fold when compared with that of the OKA and PAN samples (Table 3), leading to a significant difference in composition between the three sites as indicated by the PCA (Fig. 8a).

CHOS compounds observed in all wetland samples already showed a remarkable chemical diversity (Fig. 8b). However, the chemical dissimilarity of CHOS compounds common to both FCE samples remarkably exceeded that found in OKA and PAN, covering a substantial share of the CHOS chemical space from $\mathrm{O} / \mathrm{C}$ ratio: $0.3-0.8$ and $\mathrm{H} / \mathrm{C}$ ratio $0.6-1.7$, respectively (Fig. 8c). Here, four groups of CHOS molecules were differentiated based on their positioning in $\mathrm{H} / \mathrm{C}$ against $\mathrm{O} / \mathrm{C}$ van Krevelen diagrams (Fig. 7f): (a) saturated sulfolipids with $\mathrm{H} / \mathrm{C}$ ratio $>2$ and intermediate $\mathrm{O} / \mathrm{C}$ ratio, suggesting the presence of sulfur in elevated oxidation states; (b) unsaturated sulfolipids with a rather restricted $\mathrm{H} / \mathrm{C}$ and $\mathrm{O} / \mathrm{C}$ ratio; (c) a very large and expan-
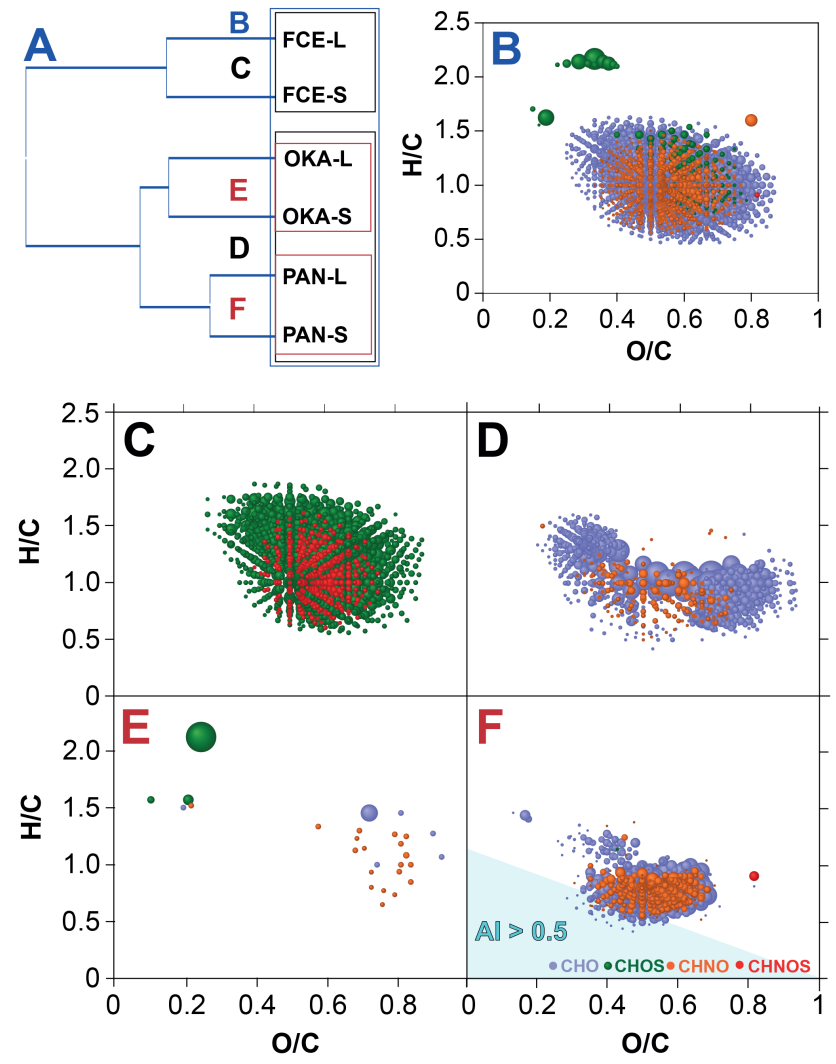

Figure 8. Comparative analysis of van Krevelen diagrams derived from negative electrospray $12 \mathrm{~T}$ FT-ICR mass spectra of all six wetlands SPE-DOM. (a) Clustering diagram based on the similarity values between the spectra of six wetlands SPE-DOM using Pearson correlation coefficient; (b) molecular compositions common to all six wetlands SPE-DOM, (c) unique molecular compositions common in FCE samples (FCE-L and FCE-S); (d) unique molecular compositions with high abundance in both PAN samples; (e) unique molecular compositions with high abundance in both OKA samples; (f) unique molecular compositions common in all four PAN and OKA. The aromaticity index AI (Koch and Dittmar, 2006) provided denotes single aromatic compounds for $\mathrm{AI}>0.5$ (bright blue triangle).

sive set of molecularly diverse CHOS molecules with a bandwidth of $\mathrm{O} / \mathrm{C}$ ratios similar to $\mathrm{CHO}$ compounds but reaching out to higher saturation (larger $\mathrm{H} / \mathrm{C}$ ratio) than the latter (Fig. 7e-f); (d) unique to FCE-S (with traces in OKA-L) was a large set of aromatic and oxygen-deficient "black sulfur" compounds (DBS; Fig. 7f; section (a) in Fig. 9a) similarly positioned like CHOS compounds in Atlantic openocean abyssopelagic SPE-DOM at $5446 \mathrm{~m}$ depth (Fig. S8 in Hertkorn et al., 2013), but covering a larger mass range (Fig. S7f). Sections (b) and (c) CHOS compounds were also observed in PAN and OKA, whereas black sulfur compounds were rare in OKA-L (Fig. S8) and virtually absent in the other samples except FCE-S. DOM-type CHOS compounds common to all six wetland samples were on average 


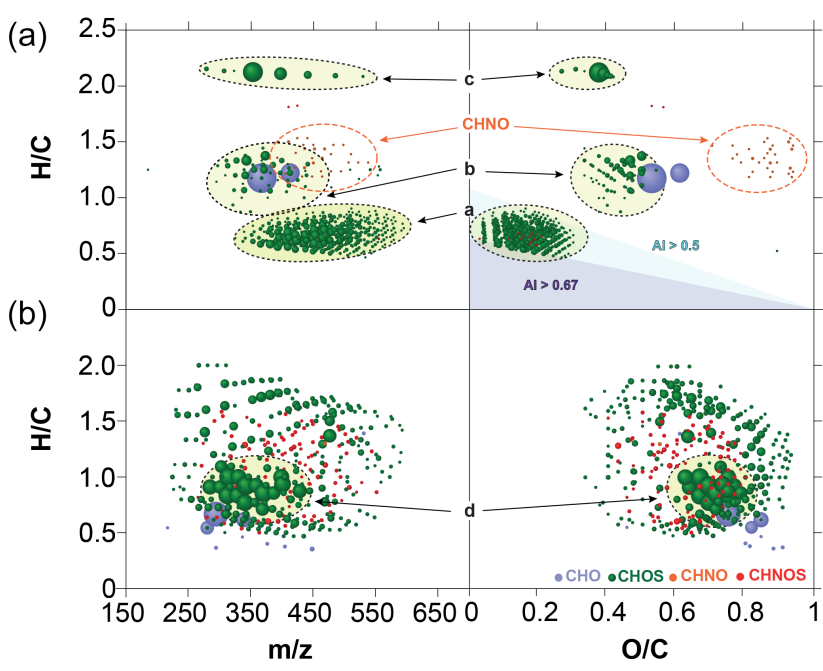

Figure 9. Comparative analysis of (left) $\mathrm{H} / \mathrm{C}$ vs. $m / z$ and (right) $\mathrm{H} / \mathrm{C}$ vs. O / C van Krevelen diagrams derived from negative electrospray 12 T FTICR mass spectra of the two Florida Coastal Everglades SPE-DOM FCE-S and FCE-L (see also Fig. 8). (a) Molecular compositions with high abundance in Florida Coastal Everglades SPE-DOM FCE-S; section (a): oxygen-deficient (poly)aromatic black sulfur; CHNOS: suite of highly oxygenated CHNOS molecules; section (b): common CHOS molecules in DOM; section (c): saturated sulfolipids. The aromaticity index AI (Koch and Dittmar, 2006) provided in the upper right van Krevelen diagram denotes single aromatic compounds for $\mathrm{AI}>0.5$ (bright blue triangle) and polyaromatic compounds for $\mathrm{AI}>0.67$ (bright purple triangle); (b) Molecular compositions with high abundance in Florida Coastal Everglades SPE-DOM FCE-L; section (d): a distinct set of oxygenrich aromatic CHOS compounds, likely associated with ether-linked aromatic units; see main text.

more saturated and oxygenated than their respective $\mathrm{CHO}$ and $\mathrm{CHNO}$ counterparts, suggesting also here the presence of sulfur in elevated oxidation states (Fig. 8b).

The CHOS compounds of both FCE samples not only differed fundamentally from those found in OKA and PAN, but were also remarkably diverse in both FCE-L and FCE$\mathrm{S}$ samples itself. Figure 9 indicates CHOS compounds present with elevated abundance in either FCE-S (Fig. 9a) or FCE-L (Fig. 9b). The most peculiar feature of FCE$\mathrm{S}$ was a hydrogen-deficient pool of (poly)aromatic CHOS compounds (section (a) mass peaks; Fig. 9a) in extended molecular series with limited degree of oxidation $(\mathrm{O} / \mathrm{C}$ ratio <0.22), ranging from $m / z \sim 300-600$. The positioning in both van Krevelen and mass-edited $\mathrm{H} / \mathrm{C}$ ratio diagrams (Fig. 9) was in accordance with that of "black sulfur" in abyssopelagic South Atlantic SPE-DOM (Fig. S8 and Fig. 16 in Hertkorn et al., 2013), but its signature was more conspicuous and showed larger richness of diverse CHOS compounds in FCE-S. While sulfur can be readily inserted into any $\mathrm{C}-\mathrm{C}$ and $\mathrm{C}-\mathrm{H}$ bond, analogous to oxygen, organic sulfur can also occupy oxidation states ranging from -2 to +6 , an option not available to oxygen. Nevertheless, the manifest oxygen deficiency of the proposed highly unsaturated CHOS molecules (section (d); Fig. 7f) suggests the presence of reduced sulfur in the form of sulfides. Aromatic CHOS molecules will then most likely occur as benzothiophene derivatives, a chemical environment of sulfur largely favored in mineral oils (Purcell et al., 2007; Liu et al., 2010; Muller et al., 2012). While both black carbon as well as black nitrogen (Wagner et al., 2015b) have been reported in the FCE (Ding et al., 2014a, b; Maie et al., 2006), the presence of this "black sulfur" was not previously observed at FCE. The environmental factors driving the high abundance of these compounds at FCE-S remain unclear but may be related to the higher fire frequency at short-hydroperiod sites and possibly soil charring. A small set of CHOS compounds with more average $\mathrm{H} / \mathrm{C}$ and $\mathrm{O} / \mathrm{C}$ ratios (section (b) mass peaks; Fig. 9a) was accompanied by a rather minor set of highly oxygenated CHNOS compounds, with an $\mathrm{O} / \mathrm{C}$ ratio $>0.75$ (Fig. 9a).

In contrast to the FCE-S, the FCE-L sample displayed an oxygenated set $(\mathrm{O} / \mathrm{C}$ ratio $>0.6)$ of a few dozen hydrogendeficient $(\mathrm{H} / \mathrm{C}$ ratio $<1.1)$ CHOS molecules in truncated molecular series and at rather low mass $(m / z<400$; Fig. $9 \mathrm{~b}$ section (d) mass peaks). These molecules were most likely composed of oxygenated aromatics connected by (some) ether bridges, which rather likely originate ultimately from plant and/or algal polyphenols. Apart from PAH-derived compounds, which are commonly rather oxygen deficient $(\mathrm{O} / \mathrm{C}$ ratio $<0.3)$, these structures represent one of the most plausible motifs of very hydrogen-deficient molecules found in DOM $(\mathrm{H} / \mathrm{C}$ ratio $<1)$. The large extent of average oxygenation makes sulfur functional groups in elevated oxidation states, e.g., sulfones, sulfonates or sulfates, likely candidates for this group of CHOS compounds.

In addition, a rather expansive cloud of abundant $\mathrm{CHOS}$ and less common CHNOS compounds at mass range $\mathrm{m} / \mathrm{z}$ 200-550, with large and variable extent of oxygenation (O / C ratio: 0.4-0.95) was prominent in FCE-L and nearabsent in FCE-S. The sizable expansion of this cloud with a huge range of $\mathrm{H} / \mathrm{C}$ ratios testified to a rather large overall diversity of these unique CHOS molecules found solely in FCE-L; CHNOS compounds seemed to follow suit but with a lesser overall diversity: highly oxygenated $(\mathrm{O} / \mathrm{C}$ ratio > 0.8) and hydrogen-rich CHNOS molecules $(\mathrm{H} / \mathrm{C}>1.6)$ were missing even if every added nitrogen carried one intrinsic hydrogen into analogous $\mathrm{CHO}$ molecular formulas. This higher molecular diversity for the FCE-L site may be driven by higher soil-derived (peat soils) DOM contributions at this site compared to FCE-S (marl soils) (Chen et al., 2013) and a higher degree of DOM preservation at this deeper, less photoexposed site.

It has to be mentioned that this cloud encircled the common molecular series of several hundreds of CHOS and CHNOS compounds found in both FCE samples (Figs. 7e$\mathrm{f}$ and $8 \mathrm{c}$ ). The significantly higher presence of sulfurcontaining molecular formulas for the FCE samples is likely 
the result of higher inputs of sulfate to the Everglades compared to the Pantanal and Okavango. Firstly, Everglades is a coastal wetland where sea spray may be an important contributor to sulfate. In addition, it is the most anthropogenically impacted wetland of the three being compared, where runoff from agricultural lands within the Everglades watershed is likely the most important contributing factor to the sulfur load of the system as it is an ingredient of fertilizer applications. The $\mathrm{CHO}$ and $\mathrm{CHNO}$ components specific for the OKA and PAN samples are shown in Fig. 8f and suggest, in agreement with the NMR data, a higher degree of oxidized, H-deficient materials at these sites compared to the FCE. This is particularly true for the PAN which show unique molecular formulas for oxidized, $\mathrm{H}$-deficient $\mathrm{CHO}$ and CHNO components (Fig. 8d), whereas molecular formulas unique for the OKA are relatively few (Fig. 8e).

Comparative analyses of van Krevelen diagrams between the six sites as shown in Fig. 8a clearly cluster the FCE samples separately from the OKA and PAN. Cluster analysis showed a clear distinction between the FCE on the one hand and the OKA and PAN samples on the other hand, with less pronounced but significant differences between the paired, long- and short-hydroperiod samples at each site (Fig. 8a). Among pairs of DOM samples, similarity according to FTICR/MS-based cluster analysis was in the order PAN > OKA > FCE (Fig. 8a), whereas one-dimensional ${ }^{1} \mathrm{H}$ NMR spectra clustered according to increasing dissimilarity in the order OKA < PAN < FCE (Fig. S2). This discrepancy is readily explained by the different recognition of aliphatic groups in FTMS (insensible) and NMR spectra (quantitative depiction). $\mathrm{CHO}$ and $\mathrm{CHNO}$ molecules ionized by negative ESI occupied rather similar expansive regions with near-average $\mathrm{H} / \mathrm{C}$ and $\mathrm{O} / \mathrm{C}$ elemental ratios (Fig. 8b). This is a common feature of DOM molecular distribution as derived from FTICR mass spectra. Here, the largest number of feasible and chemically reasonable isomeric molecules will project on single mass peaks at average $\mathrm{H} / \mathrm{C}$ and $\mathrm{O} / \mathrm{C}$ elemental ratios, contributing to larger overall mass peak amplitude - this applying even more specifically to van Krevelen diagrams, in which different molecular compositions with identical elemental ratios contribute to the same data points (Hertkorn et al., 2007; Lechtenfeld et al., 2014). Analogously, the distribution of CHO, CHOS, CHNO and CHNOS molecular series roughly coincided, with some displacement of CHOS molecules in both FCE samples, towards higher $\mathrm{H} / \mathrm{C}$ ratio (i.e., higher aliphatic character).

At first glance, the $\mathrm{H} / \mathrm{C}$ vs. $\mathrm{O} / \mathrm{C}$ (Fig. 7) as well as the $\mathrm{H} / \mathrm{C}$ vs. $m / z$ (Fig. S7) plots showed near-uniform fingerprints for OKA and PAN, covering larger areas in the van Krevelen diagrams in the case of $\mathrm{CHO}$ compared with CHNO compounds (Fig. 8b), suggesting an increased overall chemical diversity of $\mathrm{CHO}$ compounds. In addition, the paired wetland samples clustered separately for the high and low hydroperiods respectively, suggesting that molecular compositions differ among sites with different hydrol- ogy. The weighted average $\mathrm{O} / \mathrm{C}$ and $\mathrm{H} / \mathrm{C}$ values were remarkably similar for PAN and OKA showing rather marginal variance between different sites or between high and low hydroperiod (Fig. 7a-d; Table 3). In comparison, FCE-S showed a considerably decreased $\mathrm{O} / \mathrm{C}$ ratio. While computed $\mathrm{O} / \mathrm{C}$ ratios of wetland DOM exceeded those found in oceanic DOM by about 0.2 units (Table 3; Table 4 in Hertkorn et al., 2013), the $\mathrm{H} / \mathrm{C}$ ratio of wetland DOM was approximately 0.15 units higher in comparison. Even if ionization selectivity in negative ESI FTICR mass spectra applied, the ${ }^{1} \mathrm{H}$ NMR section integrals indicate analogous trends of relative saturation, or alternatively, hydrogen deficiency between wetland and marine DOM. In comparison with average wetland SPE-DOM, average open-ocean SPE-DOM showed lesser abundance of aromatics (by 2$3 \%$ ), lower proportions of OCH chemical environments (by $8 \%$ ) and, especially, higher abundance of pure aliphatics (i.e., CCCH units; by $12 \%$ ). This implies that marine DOM shows lower abundance of hydrogen-deficient (unsaturated) and higher abundance of hydrogen-rich (purely aliphatic) molecules than wetland DOM, in line with the elevated H / C ratio as derived from FTICR mass spectra. Similarly, the higher abundance of oxygen-rich OCH chemical environments in wetland DOM as seen by ${ }^{1} \mathrm{H}$ NMR section integral ( $8 \%$ relative increase) was in accordance with the increased $\mathrm{O} / \mathrm{C}$ ratio found in their FTICR mass spectra (an increase of 0.2 units).

Comparative analysis of van Krevelen diagrams (Fig. S8) obtained solely from the four PAN and OKA samples confirmed the previously observed higher similarity between PAN-L and PAN-S compared to OKA-L and OKA-S sample pairs (Figs. 7 and 8d-f). Molecular compositions with unique high abundance when derived from all six wetland samples were sparse and non-significant in the case of OKA (Fig. 8e; see also Fig. S8b), whereas molecular compositions with unique high abundance in all four OKA and PAN samples occupied a rather dense, contiguous section of hydrogendeficient $(\mathrm{H} / \mathrm{C}$ ratio $<1)$ and oxygenated $(\mathrm{O} / \mathrm{C}$ ratio $\sim 0.3-$ 0.7) $\mathrm{CHO}$ and $\mathrm{CHNO}$ molecules (Fig. 8f). In agreement with its high degree of photo-oxidation, the OKA contained higher proportions of highly oxygenated $\mathrm{CHO}(\mathrm{O} / \mathrm{C}$ ratio > 0.7) and $\mathrm{CHNO}(\mathrm{O} / \mathrm{C}$ ratio > 0.5 $)$ molecules, and a few rather abundant (and easily ionizable) sulfolipids (Fig. S8b), whereas PAN SPE-DOM displayed larger proportions of hydrogen-deficient $\mathrm{CHO}$ molecules of considerable chemical diversity and extent of oxygenation $(\mathrm{O} / \mathrm{C}$ ratio $\sim 0.2-0.9)$, and several dozens of CHNO molecules similarly positioned but with more limited range of oxygenation and, hence, overall chemical diversity (Fig. 8d).

Remarkably, with the exception of a tiny section of $\mathrm{CHO}$ molecules $(\mathrm{H} / \mathrm{C} \sim 1.1 ; \mathrm{O} / \mathrm{C} \sim 0.4)$, both $\mathrm{CHO}$ and $\mathrm{CHNO}$ molecular series for OKA and PAN nearly perfectly superimpose in the $\mathrm{H} / \mathrm{C}$ against $\mathrm{O} / \mathrm{C}$ van Krevelen diagram (Fig. 8f). It is very likely that these $\mathrm{CHO}$ molecules jointly present in PAN + OKA mainly represent oxygenated aro- 
matic molecules, possibly connected by ether linkages. This is one of the most comprehensive ways to envision such hydrogen-deficient molecules of conceivable natural product origin, and in agreement with the NMR data suggesting a higher degree of oxidized, H-deficient materials at these sites compared to the FCE. This is particularly true for the PAN which shows unique molecular formulas for oxidized, $\mathrm{H}$-deficient $\mathrm{CHO}$ and $\mathrm{CHNO}$ components, whereas molecular formulas unique for the OKA are relatively few (Figs. 8e$\mathrm{f}$ and $\mathrm{S} 8 \mathrm{~b}-\mathrm{c})$.

\section{Conclusions and biogeochemical significance}

Very detailed molecular analyses of DOM samples from three different subtropical freshwater wetlands suggest, in agreement with previous reports on riverine and marine DOM characterizations, that many of the bulk molecular characteristics in freshwater DOM are shared by ecosystems despite being very different in their environmental settings (Repeta et al., 2002; Jaffé et al., 2012). Nevertheless, organic structural spectroscopy provided evidence for wetlandspecific molecular assemblies. NMR and FTMS analysis provided exceptional coverage of wetland SPE-DOM composition and structure, confirming individual wetland organic matter molecular characteristics. Those were directly revealed in ${ }^{1} \mathrm{H}$ NMR spectra, while extensive mathematical analysis was mandatory to discern analogous distinction in FTICR mass spectra, which show extensive projection of structural variance on the primary measured variable. These detailed analyses revealed significant variations in the molecular composition that can, in some cases, be controlled by site-specific environmental conditions. Among those are hydrological drivers such as hydroperiod (lengths and depths of inundation), resulting in variations in light penetration and associated photochemical processes, along with seasonal drying of surface soils and associated aerobic oxidation processes. Other drivers include (i) external sources of sulfur, such as agricultural activities and sea spray, resulting in the formation of a variety of sulfur compounds in DOM, (ii) fire regime, possibly causing soil OM charring during wildfires and (iii) natural DOM source variations and source strength in the contribution from vascular plants, grasses and aquatic vegetation including microbial contributions from periphyton. As such, while not all molecular differences could be explained through one or more of these drivers, this study illustrates for the first time the extensive molecular diversity and compositional complexity of DOM in wetlands, and as such should serve as a database for future characterization efforts. Further detailed molecular-level characterizations of wetland DOM are encouraged as a means to better understand spatial and seasonal variability in sources, transformations and reactivity, which can be ultimately used to aid in constraining carbon cycling models.

\author{
The Supplement related to this article is available online \\ at doi:10.5194/bg-13-2257-2016-supplement.
}

Author contributions. N. Hertkorn performed the NMR study, contributed to the study design, data interpretation and actively participated in the writing of the paper; M. Harir performed the FTICR/MS analyses and data manipulation and participated in data interpretation; K. M. Cawley collected samples from Okavango Delta and performed the optical properties study; P. Schmitt-Kopplin provided support for the FT-ICR/MS analyses and general data interpretations; R. Jaffé collected Pantanal and Everglades samples, participated in all data interpretations, took the lead in coordinating this study, writing this paper, and generated funding in support of this research. All authors provided significant input to the final manuscript.

Acknowledgements. The authors acknowledge the financial support from the George Barley Chair and the Florida Coastal Everglades LTER (DEB - 1237517; to R. Jaffé) for funding this research. We are grateful to C. Nunes, N. Rodriguez, N. Mladenov and P. Wolski who assisted in field logistics and to S. Thaller (HMGU) who expertly assisted in NMR sample preparation and assembly of figures. K. M. Cawley thanks Everglades National Park for a Post-doctoral fellowship. This is SERC contribution number 781.

Edited by: G. Herndl

\section{References}

Aluwihare, L. I. and Repeta, D. J.: A comparison of the chemical characteristics of oceanic DOM and extracellular DOM produced by marine algae, Mar. Ecol.-Prog. Ser., 186, 105-117, 1999.

Amon, R. M. W. and Benner, R.: Bacterial utilization of different size classes of dissolved organic matter, Limnol. Oceanogr., 41, 41-51, 1996a.

Amon, R. M. W. and Benner, R.: Photochemical and microbial consumption of dissolved organic carbon and dissolved oxygen in the Amazon River system, Geochim. Cosmochim. Ac., 60, 17831792, 1996 b.

Battin, T. J., Luyssaert, S., Kaplan, L. A., Aufdenkampe, A. K., Richter, A., and Tranvik, L. J.: The boundless carbon cycle, Nat. Geosci., 2, 598-600, 2009.

Bell, N. G. A., Michalchuk, A. A. L., Blackburn, J. W. T., Graham, M. C., and Uhrin, D.: Isotope-filtered 4-D NMR spectroscopy for structure determination of humic substances, Angew. Chem.-Int. Edit., 54, 1-5, 2015.

Blough, N. V. and Green, S. A.: Spectroscopic characterization and remote sensing on non-living organic matter, in: The role of nonliving organic matter on the earth's carbon cycle, edited by: Zepp, R. G. and Sonntag, C., John Wiley and Sons, New York, USA, 23-45, 2009.

Cawley, K., Wolski, P., Mladenov, N., and Jaffé, R.: Dissolved organic matter biogeochemistry along a transect of the Okavango Delta, Botswana, Wetlands, 32, 475-486, 2012. 
Chen, M. and Jaffé, R.: Photo- and bio-reactivity patterns of dissolved organic matter from biomass and soil leachates and surface waters in a subtropical wetland, Water Res., 61, 181-190, 2014.

Chen, M., Price, R. M., Yamashita, Y., and Jaffé, R.: Comparative study of dissolved organic matter from groundwater and surface water in the Florida coastal Everglades using multi-dimensional spectrofluorometry combined with multivariate statistics, Appl. Geochem., 25, 872-880, 2010.

Chen, M., Maie, N., Parish, K., and Jaffé, R.: Spatial and temporal variability of dissolved organic matter quantity and composition in an oilgotrophic subtropical coastal wetland, Biogeochemistry, $115,167-183,2013$.

D’Andrilli, J., Dittmar, T., Koch, B. P., Purcell, J. M., Marshall, A. G., and Cooper, W. T.: Comprehensive Characterization of Marine Dissolved Organic Matter by FT-ICR Mass Spectrometry with Electrospray and Atmospheric Pressure Photoionization, Rapid Commun. Mass Sp., 24, 643-650, 2010.

Ding, Y., Cawley, K., Nunes, C., and Jaffé, R., Environmental dynamics of dissolved black carbon in wetlands, Biogeochemistry, 119, 259-273, 2014a.

Ding, Y., Watanabe, A., and Jaffé, R.: Dissolved black nitrogen $(\mathrm{DBN})$ in freshwater environments: Source and land to ocean flux assessment, Org. Geochem., 68, 1-4, 2014b.

Dittmar, T., Hertkorn, N., and Katner, G.: A simple and efficient method for the solid-phase extraction of dissolved organic matter (SPE-DOM) from seawater, Limnol. Oceanogr., 6, 230-235, 2008.

Einsiedl, F., Hertkorn, N., Wolf, M., Frommberger, M., SchmittKopplin, P., and Koch, B. P.: Rapid biotic molecular transformation of fulvic acids in a karst aquifer, Geochim. Cosmochim. Ac., 71, 5474-5482, 2007.

Ellery, W. N., McCarthy, T. S., and Smith, N. D.: Vegetation, hydrology and sedimentation patterns on the major distributary system of the Okavango Delta, Botswana, control of a river system by vegetation, Wetlands, 23, 357-375, 2003.

Fellman, J. B., Hood, E., and Spencer, R. G. M.: Fluorescence spectroscopy opens new windows into dissolved organic matter dynamics in freshwater ecosystems: a review, Limnol. Oceanogr., 55, 2452-2462. 2010.

Flerus, R., Koch, B. P., Schmitt-Kopplin, P., Witt, M., and Kattner, G.: Molecular level investigation of reactions between dissolved organic matter and extraction solvents using FT-ICR MS, Mar. Chem., 124, 100-107, 2011.

Foden, T., Sivyer, D. B., Mills, D. K., and Devlin, M. J.: Spatial and temporal distribution of chromophoric dissolved organic matter (CDOM) fluorescence and its contribution to light attenuation in UK waterbodies, Estuar. Coast. Shelf S., 79, 707-717, 2008.

Gieske, A.: Modelling outflow from the Jao/Boro river system in the Okavango delta, Botswana, J. Hydrol., 193, 214-239, 1997.

Gumbricht, T., McCarthy, J., and McCarthy, T. S.: Channels, wetlands and islands in the Okavango Delta, Botswana, and their relation to hydrological and sedimentological processes, Earth Surf. Proc. Land., 29, 15-29, 2004.

Hedges, J. I., Eglinton, G., Hatcher, P. G., Kirchman, D. L., Arnosti, C., Derenne, S., Evershed, R. P., Kogel-Knabner, I., de Leeuw, J. W., Littke, R., Michaelis, W., and Rullkotter, J.: The molecularly-uncharacterized component of nonliving or- ganic matter in natural environments. Org. Geochem., 31, 945958, 2000.

Helms, J. R., Stubbins, A., Ritchie, J. D., and Minor, E. C.: Absorption spectral slopes and slope ratios as indicators of molecular weight, source, and photobleaching of chromophoric dissolved organic matter, Limnol. Oceanogr., 53, 955-969, 2008.

Hertkorn, N., Benner, R., Frommberger, M., Schmitt-Kopplin, P., Witt, M., Kaiser, K., Kettrup, A., and Hedges, J. I.: Characterization of a major refractory component of marine dissolved organic matter, Geochim. Cosmochim. Ac., 70, 2990-3010, 2006.

Hertkorn, N., Ruecker, C., Meringer, M., Gugisch, R., Frommberger, M., Perdue, E. M., Witt, M., and Schmitt-Kopplin, P.: High-precision frequency measurements: indispensable tools at the core of the molecular-level analysis of complex systems, Anal. Bioanal. Chem., 389, 1311-1327, 2007.

Hertkorn, N., Frommberger, M., Witt, M., Koch, B. P., SchmittKopplin, P. and, Perdue, E. M.: Natural organic matter and the event horizon of mass spectrometry, Anal. Chem., 80, 89088919, 2008.

Hertkorn, N., Harir, M., Koch, B. P., Michalke, B., and SchmittKopplin, P.: High-field NMR spectroscopy and FTICR mass spectrometry: powerful discovery tools for the molecular level characterization of marine dissolved organic matter, Biogeosciences, 10, 1583-1624, doi:10.5194/bg-10-1583-2013, 2013.

Jaffé, R., McKnight, D. M., Maie, N., Cory, R. M., McDowell, W. H., and Campbell, J. L.: Spatial and temporal variations in DOM composition in ecosystems: The importance of long-term monitoring of optical properties, J. Geophys. Res.-Biogeo., 113, G04032, doi:10.1029/2008JG000683, 2008.

Jaffé, R., Yamashita, Y., Maie, N., Cooper, W. T., Dittmar, T., Dodds, W. K., Jones, J. B., Myoshi, T., Ortiz-Zayas, J. R., Podgorski, D. C., and Watanabe, A.: Dissolved Organic Matter in Headwater Streams: Compositional Variability Across Climatic Regions, Geochim. Cosmochim. Ac., 94, 95-108, 2012.

Jaffé, R., Ding, Y., Niggemann, J., Vähätalo, A., Stubbins, A., Spencer, R., Campbell, J. L., and Dittmar T.: Global mobilization of charcoal from soils via dissolution and subsequent riverine transport to the oceans, Science, 340, 345-347, 2013.

Jaffé, R., Cawley, K. M., and Yamashita, Y.: Applications of excitation emission matrix fluorescence with parallel factor analysis (EEM-PARAFAC) in assessing environmental dynamics of natural dissolved organic matter (DOM) in aquatic environments: A review, Advances in the Physicochemical Characterization of Organic Matter, ACS Series, edited by: Rosario, F. 27-73, 2014.

Junk, W. J., Brown, M., Campbell, I. C., Finlayson, M., Gopal, B., Ramberg, L., and Warner, B. G.: The comparative biodiversity of seven globally important wetlands: a synthesis, Aquat. Sci., 68, 400-414, 2006a.

Junk, W. J., Nunes da Cunha, C., Wantzen, K. M., Petermann, P., Strüssmann, C., Marques, M. I., and Adis, J.: Biodiversity and its conservation in the Pantanal of Mato Grosso, Brazil. Aquat. Sci., 68, 278-309, 2006b.

Junk, W. T. and Nunes da Cunha, C.: Pantanal: a large South American wetland at a crossroads, Ecol. Eng., 24, 391-401, 2005.

Kaiser, E., Simpson, A. J., Dria, K. J., Sulzberger, B. and Hatcher, P. G.: Solid-state and multidimensional solution-state NMR of solid phase extracted and ultrafiltered riverine dissolved organic matter, Environ. Sci. Technol., 37, 2929-2935, 2003. 
Kellerman, A. M., Kothawala, D. N., Dittmar, T., and Tranvik, L. J.: Persistence of dissolved organic matter in lakes related to its molecular characteristics, Nat. Geosci. Lett., 8, 454-457, 2015.

Koch, B. P. and Dittmar, T.: From mass to structure: an aromaticity index for high-resolution mass data of natural organic matter, Rapid Commun. Mass Sp., 20, 926-932, 2006.

Koch, B. P., Witt, M. R., Engbrodt, R., Dittmar, T., and Kattner, G.: Molecular formulae of marine and terrigenous dissolved organic matter detected by electrospray ionization Fourier transform ion cyclotron resonance mass spectrometry, Geochim. Cosmochim. Ac., 69, 3299-3308, 2005.

Koch, B. P., Dittmar, T., Witt, M., and Kattner, G.: Fundamentals of molecular formula assignment to ultrahigh resolution mass data of natural organic matter, Anal. Chem., 79, 1758-1763, 2007.

Kujawinski, E. B.: Electrospray ionization Fourier transform ion cyclotron resonance mass spectrometry (ESI FT-ICR MS): Characterization of complex environmental mixtures, Environ. Forensics, 3, 207-216, 2002.

Kujawinski, E. B., Longnecker, K., Blough, N. V., Del Vecchio, R., Finlay, L., Kitner, J. B., and Giovannoni, S. J.: Identification of possible source markers in marine dissolved organic matter using ultrahigh resolution mass spectrometry, Geochim. Cosmochim. Ac., 73, 4384-4399, 2009.

Lam, B., Alaee, M., Lefebvre, B., Moser, A., Williams, A., and Simpson, A. J.: Major Structural Components in Freshwater Dissolved Organic Matter, Environ. Sci. Technol., 41, 2840-2847, 2007.

Lechtenfeld, O. J., Kattner, G., Flerus, R., McCallister, S. L., Schmitt-Kopplin, P., and Koch, B. P.: Molecular transformation and degradation of refractory dissolved organic matter in the Atlantic and Southern Ocean, Geochim. Cosmochim. Ac., 126, 321-337, 2014.

Liu, P., Xu, C., Shi, Q., Pan, N., Zhang, Y., Zhao, S., and Chung, K. H.: Characterization of Sulfide Compounds in Petroleum: Selective Oxidation Followed by Positive-Ion Electrospray Fourier Transform Ion Cyclotron Resonance Mass Spectrometry, Anal. Chem., 82, 6601-6606, 2010.

Maie, N., Yang, C.-Y., Miyoshi, T., Parish, K., and Jaffé, R.: Chemical characteristics of dissolved organic matter in an oligotrophic subtropical wetland/estuarine ecosystem, Limnol. Oceanogr., 50, 23-35, 2005.

Maie, N., Parish, K., Watanabe, A., Knicker, H., Benner, R., Abe, T., Kaiser, K., and Jaffé, R.: Chemical characteristics of dissolved organic nitrogen in an oligotrophic subtropical coastal ecosystem, Geochim. Cosmochim. Ac., 70, 4491-4506, 2006.

Martinez, A. T., Rencoret, J., Marques, G., Gutierrez, A., Ibarra, D., Jimenez-Barbero, J., and del Rio, J. C.: Monolignol acylation and lignin structure in some nonwoody plants: A 2-D NMR study, Phytochemistry, 69, 2831-2843, 2008.

McCarthy, J. M., Gumbricht, T., McCarthy, T., Frost, P., Wessels, K., and Seidel, F.: Flooding patterns of the Okavango wetland in Botswana between 1972 and 2000, Ambio, 32, 453-457, 2003.

McCaul, M. V., Sutton, D., Simpson, A. J., Spence, A., McNally, D. J., Moran, B.W., Goel, A., O'Connor, B., Hart, K. and Kelleher, B. P.: Composition of dissolved organic matter within a lacustrine environment, Environ. Chem., 8, 146-154, 2011.

McKnight, D. M., Boyer, E. W., Westerhoff, P. K., Doran, P. T., Kulbe, T., and Andersen, D. T.: Spectorflourometric characterization of dissolved organic matter for indication of precursor organic material and aromaticity, Limnol. Oceanogr., 46, 38-48, 2001.

Minor, E. C., Steinbring, C. J., Longnecker, K., and Kujawinski, E. B.: Characterization of dissolved organic matter in Lake Superior and its watershed using ultrahigh resolution mass spectrometry, Org. Geochem., 43, 1-11, 2012.

Minor, E. C., Swenson, M., Mattson, B. M., and Oyler, A. R.: Structural characterization of dissolved organic matter: A review of current techniques for isolation and analysis, Environmental Science: Processes and Impacts, 16, 2064-2079, 2014.

Mladenov, N., McKnight, D. M., Macko, S. A., Norris, M., Cory, R. M., and Ramberg, L.: Chemical characterization of DOM in channels of a seasonal wetland, Aquat. Sci., 69, 456-471, 2007.

Muller, H., Adam, F. M., Panda, S. K., Al-Jawad, H.-H., and AlHajji, A. A.: Evaluation of Quantitative Sulphur Speciation in Gas Oils by Fourier Transform Ion Cyclotron Resonance Mass Spectrometry: Validation by Comprehensive Two-Dimensional Gas Chromatography. J. Am. Soc. Mass Spectr., 23, 806-815, 2012.

Ohno, T.: Fluorescence inner-filtering correction for determining the humification index of dissolved organic matter, Environ. Sci. Technol., 36, 742-746, 2002.

Panagiotopoulos, C., Repeta, D. J., and Johnson, C. G.: Characterization of methyl sugars, 3-deoxysugars and methyl deoxysugars in marine high molecular weight dissolved organic matter, Org. Geochem., 38, 884-896, 2007.

Perdue, E. M. and Ritchie, J. D.: Dissolved Organic Matter in Fresh Waters. in: Treatise on Geochemistry, edited by: Holland, H. D. and Tuerekian, K. K., Surface and Ground Water; Weathering, Erosion and Soils, 5, 273-318, 2003.

Perdue, E. M., Hertkorn, N., and Kettrup, A.: Substitution patterns in aromatic rings by increment analysis. Model development and application to natural organic matter, Anal. Chem., 79, 1010 1021, 2007.

Purcell, J. M., Jayal, P., Kim, D.-G., Rodgers, R. P., Hendrickson, C. L., and Marshall, A. G.: Sulphur Speciation in Petroleum: Atmospheric Pressure Photoionization or Chemical Derivatization and Electrospray Ionization Fourier Transform Ion Cyclotron Resonance Mass Spectrometry, Energy Fuel., 21, 2869-2874, 2007.

Ralph, J., Hatfield, R. D., Piquemal, J., Yahiaoui, N., Pean, M., Lapierre, C., and Boudet, A. M.: NMR characterization of altered lignins extracted from tobacco plants down-regulated for lignification enzymes cinnamyl-alcohol dehydrogenase and cinnamoyl-CoA reductase, P. Natl. Acad. Sci. USA, 95, 12803 12808, 1998.

Repeta, D. J., Quan, T. M., Aluwihare, L. I., and Accardi, A.: Chemical characterization of high molecular weight dissolved organic matter in fresh and marine waters, Geochim. Cosmochim. Ac., 66, 955-962, 2002.

Schmitt-Kopplin, P., Gelencsér, A., Dabek-Zlotorzynska, E., Kiss, G., Hertkorn, N., Harir, M., Hong, Y., and Gebefügi, I.: Analysis of the unresolved organic fraction in atmospheric aerosols with ultrahigh resolution mass spectrometry and nuclear magnetic resonance spectroscopy: Organosulfates as photochemical smog constituents, Anal. Chem., 82, 8017-8026, 2010.

Sleighter, R. L. and Hatcher, P. G.: The application of electrospray ionization coupled to ultrahigh resolution mass spectrometry for the molecular characterization of natural organic matter, J. Mass Spectrom., 42, 559-574, 2007. 
Spencer, R. G. M., Hernes, P. J., Aufdenkampe, A. K., Baker, A., Gulliver, P., Stubbins, A., Aiken, G., Dyda, R. Y., Butler, K. D., Mwambai, V. L., Mangangu, A. M., Wabakanghanzi, J. N., and Six, J.: An initial investigation into the organic matter biogeochemistry of the Congo River, Geochim. Cosmochim. Ac., 84, 614-626, 2012.

Stubbins, A., Niggemann, J., and Dittmar, T.: Photo-lability of deep ocean dissolved black carbon, Biogeosciences, 9, 1661-1670, doi:10.5194/bg-9-1661-2012, 2012.

Stubbins, A., Lapierre, J.-F., Berggren, M., Prairie, Y. T., Dittmar, T., and del Giorgio P. A.: What's in an EEM? Molecular signatures associated with dissolved organic fluorescence in boreal Canada, Environ. Sci. Technol., 48, 10598-10606, 2014.

Tfaily, M. M., Corbett, J. E., Lin, X., Chanton, J. P., Glaser, P. H., Cawley, K. M., Jaffé, R., and Cooper, W. T.: Variations in the composition of porewater dissolved organic matter across ecological and hydrological gradients in a northern peatland, Photochem. Photobiol., 91, 684-695, 2015.

Wagner, S., Jaffé, R., Cawley, K., Dittmar, T., and Stubbins, A.: Associations between the molecular and optical properties of dissolved organic matter in the Florida Everglades: a model coastal wetland system, Frontiers in Marine Biogeochemistry, 3, 66, doi:10.3389/fchem.2015.00066, 2015a.

Wagner, S., Dittmar, T., and Jaffé, R.: Molecular characterization of dissolved black nitrogen by electrospray ionization Fourier transform ion cyclotron resonance mass spectrometry, Org. Geochem., 79, 21-30, 2015b.

Weishaar, J. L., Aiken, G. R., Bergamaschi, B. A., Fram, M. S., Fujii, R., and Mopper, K.: Evaluation of specific ultraviolet absorbance as an indicator of the chemical composition and reactivity of dissolved organic carbon, Environ. Sci. Technol., 37, 47024708, 2003.

Wen, J.-L., Sun, S.-L., Xue, B.-L., and Sun, R.-C.: Recent Advances in Characterization of Lignin Polymer by Solution-State Nuclear Magnetic Resonance (NMR) Methodology, Materials, 6, 359$391,2013$.
Wolski, P., Savenije, H. H. G., Murray-Hudson, M., and Gumbricht, T.: Modelling of the flooding in the Okavango Delta, Botswana, using a hybrid reservoir-GIS model, J. Hydrol., 331, 58-72, 2006.

Woods, G. C., Simpson, M. J., Koerner, P. J., Napoli, A., and Simpson, A. J.: HILIC-NMR: towards the identification of individual molecular components in dissolved organic matter, Environ. Sci. Technol., 45, 3880-3886, 2011.

Woods, G. C., Simpson, M. J., and Simpson, A. J.: Oxidized sterols as a significant component of dissolved organic matter: Evidence from 2-D HPLC in combination with 2-D and 3D NMR spectroscopy, Water Res., 46, 3398-3408, 2012.

Yamashita, Y. and Jaffé, R.: Characterizing the Interactions between Trace Metals and Dissolved Organic Matter Using ExcitationEmission Matrix and Parallel Factor Analysis, Environ. Sci. Technol., 42, 7374-7379, 2008.

Yamashita, Y. and Tanoue, E.: Chemical characterization of proteinlike fluorophores in DOM in relation to aromatic amino acids, Mar. Chem., 82, 255-271, 2003.

Yamashita, Y., Scinto, L., Maie, N., and Jaffé, R.: Assessing the environmental dynamics of dissolved organic matter in an oligotrophic subtropical wetland by optical means, Ecosystems, 13, 1006-1019, 2010.

Yuan, T.-Q., Sun, S.-N., Xu, F., and Sun, R.-C.: Characterization of Lignin Structures and Lignin-Carbohydrate Complex (LCC) Linkages by Quantitative ${ }^{13} \mathrm{C}$ and 2-D HSQC NMR Spectroscopy, J. Agr. Food Chem., 59, 10604-10614. 2011.

Yelle, D. J., Ralph, J., and Frihart, C. R.: Characterization of nonderivatized plant cell walls using high-resolution solution-state NMR spectroscopy, Magn. Reson. Chem., 46, 508-517, 2008.

Zhang, F., Harir, M., Moritz, F., Zhang, J., Witting, M., Wu, Y., Schmitt-Kopplin, P., Fekete, A., Gaspar, A., and Hertkorn, N.: Molecular and structural characterization of dissolved organic matter during and post cyanobacterial bloom in Taihu by combination of NMR spectroscopy and FTICR mass spectrometry, Water Res., 57, 280-294, 2014. 